\title{
MANCHESTER
}

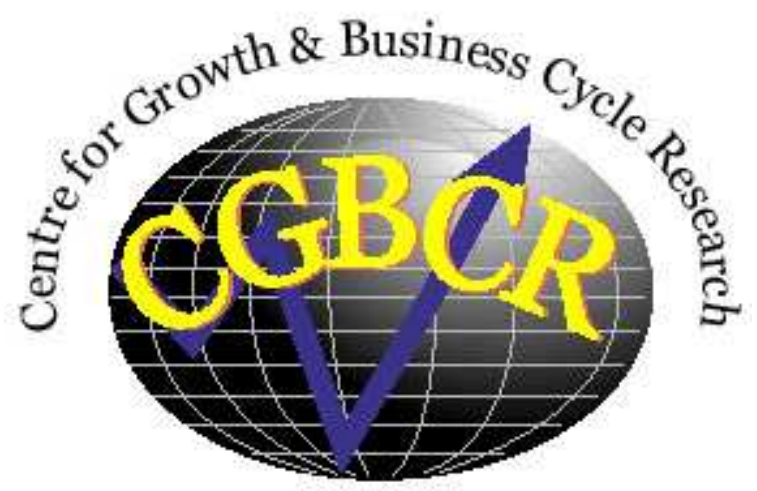

Discussion Paper Series

\section{Innovation, Public Capital, and Growth}

By

\section{Pierre-Richard Agénor and Kyriakos C. Neanidis}

Centre for Growth and Business Cycle Research, Economic Studies, University of Manchester, Manchester, M13 9PL, UK

February2010

Number 135

Download paper from:

http://www.socialsciences.manchester.ac.uk/cgbcr/discussionpape rs/index.html 


\title{
Innovation, Public Capital, and Growth
}

\author{
Pierre-Richard Agénor* and Kyriakos C. Neanidis** \\ Shorter version published in the Journal of Macroeconomics
}

\begin{abstract}
This paper studies interactions between innovation, public capital, and human capital in an OLG model of endogenous growth. Public capital affects growth not only through productivity, but also through innovation capacity and human capital accumulation. Numerical simulations, based on a calibrated version of the model, are used to illustrate these channels. Panel data regressions are presented next; they show that higher innovation performance promotes growth directly, whereas public capital has both direct and indirect growth effects by promoting human capital accumulation and innovation capacity. Elasticity estimates derived from simultaneous equation techniques show that the general equilibrium effects of public capital on steady-state output per capita (which account for indirect effects) are significantly higher than those derived from single equation methods.
\end{abstract}

JEL Classification Numbers: C33, H54, O31, O41.

*Hallsworth Professor of International Macroeconomics and Development Economics, School of Social Sciences, University of Manchester, and co-Director, Centre for Growth and Business Cycle Research (CGBCR); ** Senior Lecturer in Macroeconomics, School of Social Sciences, University of Manchester, and CGBCR. We are grateful to participants at various seminars andan anonymous referee for helpful comments, and to Baris Alpaslan for research assistance. 


\section{Introduction}

The link between human capital, innovation, and growth has been the subject of numerous analytical and empirical contributions. Starting from the seminal contributions of Romer (1990), Grossman and Helpman (1991), and Aghion and Howitt (1992), a number of studies have proposed integrated models in which R\&D and human capital accumulation are engines of growth, by emphasizing the complementarity between these two factors for the process of development; these studies include Redding (1996), Arnold (1998), Funke and Strulik (2000), Strulik (2005), Grossmann (2007), Iacopetta (2010), Gómez (2011), Sequeira (2011), Chen and Funke (2013), and Gómez and Sequeira (2013).

At the same time the link between public capital, innovation, and growth has not received much attention in the literature. In one of the few existing contributions, Schiffbauer (2007) developed a Romer-type model in which government spending on infrastructure reduces transportation costs associated with intermediate goods. However, he does not discuss public policy, and the potential trade-offs associated with the provision of infrastructure and other services by the government. Yet, this is a critical issue; if governments have access to limited resources to cover their expenditure, different types of government interventions may entail dynamic trade-offs at the macroeconomic level - even though at the microeconomic or sectoral level these interventions are largely complementary. In addition, different types of government intervention may generate spillover effects on other sectors, which may have an indirect impact on innovation capacity. If indeed lack of infrastructure or low quality of tertiary education are key constraints on research and development activities, increasing spending on infrastructure or universities may ultimately prove to be more efficient to stimulate innovation than, say, subsidies to research activities in the private sector.

To address these issues, this paper develops an overlapping-generations (OLG) model in which education, public capital, and innovation are all determinants of long-run growth. In the model, public capital affects the economy in a number of ways - through productivity in the production of final goods (in the standard Barro (1990) tradition), but also through innovation capacity and the economy's ability to produce human capital. This last channel is consistent with a number of studies that have documented a positive impact of infrastructure services on educational attainment (Agénor (2012)). As a consequence of these various channels, the tradeoffs involved in the allocation of public spending are more involved; depending on production elasticities, the best way to foster innovation activity in the private sector is not necessarily through direct public subsidies. 
Our analytical framework delivers several important testable implications with respect to the effects of public infrastructure and public R\&D spending on economic growth. The former operates both directly and indirectly (through the capacity to innovate and the accumulation of human capital) while the latter depends on the way R\&D spending is financed. Moreover, the impact of infrastructure may operate, both directly and indirectly, in a nonlinear fashion. Numerical simulations, based on a calibrated version of the model, are first used to illustrate some of these channels. We then test these implications by using a sample of 38 industrial and developing countries for the period 1981-2008 with a variety of econometric procedures and alternative definitions of the key variables. The estimation techniques include standard panel regression techniques as well as techniques that address potential endogeneity (dynamic GMM techniques and 3SLS). The 3SLS system approach, in particular, allows us to capture some of the main interactions mentioned earlier. In addition, we also account for the impact of the quality of infrastructure on growth.

To preview our empirical results, we find that higher innovation performance is conducive to per capita income growth while the stock of public capital has both direct and indirect growth effects by raising both human capital and the capacity to innovate. We also find evidence of quality effects of infrastructure and empirical support for the "critical mass" hypothesis of public capital, in line with several recent contributions (see Röller and Waverman (2001), Kellenberg (2009), Agénor (2010), and Czernich et al. (2011)). Taking proper account of the government's budget constraint, and the joint determination of the key endogenous variables, our estimates also suggest that public spending on $R \& D$ contributes to growth by fostering innovation. Further, we use the coefficient estimates to calculate various elasticity parameters, thus offering a direct link to the theoretical model developed. Elasticity estimates derived from simultaneous equation techniques suggest that the general equilibrium effects of public capital on growth are significantly higher than those derived from single equation methods. Indeed, while our direct estimates are close to the average of 0.17 reported in the review by Bom and Ligthart (2014), which focuses on studies based on single equation techniques, our estimate based on simultaneous equation techniques is in the range of $0.2-0.4$, depending on the type of infrastructure.

The paper continues as follows. Section 2 presents the model. In doing so we pay particular attention to the production functions for goods, human capital, and ideas, given that our estimation methodology is directly related to them and the parameters that characterize the externalities associated with public capital. Section 3 derives the equilibrium growth rate. Section 4 calibrates the model and studies the growth effects of an increase in public investment in infrastructure, under alterna- 
tive financing assumptions, and for different values of the parameters that capture the externalities associated with infrastructure. Section 5 presents our econometric methodology and findings. Section 6 offers some concluding remarks.

\section{The Economy}

We consider an OLG economy where individuals live for two periods, adulthood and old age. Each individual is endowed with one unit of time in each period of life. Adults supply labor inelastically; thus, we abstract from time allocation issues, and wages in adulthood are the only source of income. ${ }^{1}$ In old age time is allocated entirely to lesure. Savings can be held only in the form of physical capital. Agents have no other endowments, except for an initial stock of physical capital at $t=0$, which is the endowment of an initial old generation. In adulthood, each individual has one child; total population is thus constant and the size of each cohort is set to $\bar{N}$.

In addition to individuals, the economy is populated by firms and a government. There are four sectors in the economy: the first produces a final good, the second intermediate inputs (which depreciate fully after use), the third human capital (which is nonrival), and the fourth conducts research and development (R\&D). Labor is used in the production of the final good and ideas, and moves freely across sectors. In addition to labor, firms producing the final good use also human and private physical capital, public infrastructure, and intermediate goods. The good can be either consumed in the period it is produced, or stored to yield physical capital at the beginning of the following period.

The government invests in infrastructure and spends on education, subsidies to innovation, and some other items. It finances its expenditure by taxing wages. It cannot borrow and therefore must run a balanced budget in each period.

\section{$2.1 \quad$ Individuals}

Let $c_{t+j}^{t}$ denote consumption at period $t+j$ of a person born at the beginning of period $t$, with $j=0,1$. The discounted utility of an individual born at $t$ is given by

$$
U_{t}=\eta_{C} \ln c_{t}^{t}+\frac{\ln c_{t+1}^{t}}{1+\rho}
$$

\footnotetext{
${ }^{1}$ See Grossmann (2007) for an R\&D-based OLG model of growth with endogenous labor allocation. His focus is on a comparison between R\&D subsidies to firms and the public provision of advanced education - an issue that also entails the type of trade-offs in government spending alluded to earlier.
} 
where $\rho>0$ is the subjective discount rate and and $\eta_{C}>0$ a parameter that measures the individual's preference for current consumption.

Because taxes are levied only on middle-aged workers, the period-specific budget constraints are given by

$$
\begin{gathered}
c_{t}^{t}+s_{t}=(1-\tau) e_{t} w_{t}, \\
c_{t+1}^{t}=\left(1+r_{t+1}\right) s_{t},
\end{gathered}
$$

where $w_{t}$ is the economy-wide wage rate, $e_{t}$ individual human capital, $\tau \in(0,1)$ a constant tax rate, $s_{t}$ savings, and $r_{t+1}$ the rate of return on holding (physical) assets between periods $t$ and $t+1$. Households maximize (1), subject to (2) and (3), with respect to $c_{t}^{t}$ and $c_{t+1}^{t}$.

\subsection{Production of the Final Good}

The final good is produced by identical competitive firms of mass 1 , indexed by $i$. Production requires the use of effective labor, given by the product of average human capital, $E_{t}$, and employment, $N_{i, t}^{Y}$, private capital, $K_{t}^{P, i}$, public infrastructure, $K_{t}^{I}$, and a combination of $M_{t}$ intermediate inputs (or brands), $x_{s, t}^{i}$, where $s=1, \ldots M_{t}$.

The production function of firm $i$ takes therefore the form

$$
Y_{t}^{i}=\left[\frac{K_{t}^{I}}{\left(K_{t}^{P}\right)^{\zeta_{K}}\left(N_{t}^{Y}\right)^{\zeta_{N}}}\right]^{\varepsilon}\left(K_{t}^{P, i}\right)^{\alpha}\left(E_{t} N_{i, t}^{Y}\right)^{\beta}\left[\sum_{1}^{M_{t}}\left(x_{s, t}^{i}\right)^{\eta}\right]^{\gamma / \eta}
$$

where $\alpha, \beta, \gamma \in(0,1), \eta \in(0,1), \varepsilon>0, \zeta_{K}, \zeta_{N}>0, K_{t}^{P}=\int_{0}^{1} K_{t}^{P, i} d i$ the aggregate private capital stock, $N_{t}^{Y}=\int_{0}^{1} N_{i, t}^{Y} d i$ total employment in the final good sector, and $1 /(1-\eta)>1$ is (the absolute value of) the elasticity of demand for each intermediate good. As in Romer (1990), each new innovation involves the production of a new intermediate good. In addition, the production function distinguishes between the returns to specialization, as measured by $\gamma$, and the parameter that determines the demand elasticity, $\eta$. We assume constant returns to scale in private inputs, so that $\alpha+\beta+\gamma=1$.

Specification (4) also implies that public capital, although nonexcludable, is partially rival and subject to congestion, as measured by the aggregate private capital stock and the total number of workers in the final good sector. ${ }^{2}$ The strength of congestion effects is measured by the parameters $\zeta_{K}$ and $\zeta_{N}$.

\footnotetext{
${ }^{2}$ Instead of the aggregate capital stock, congestion could be measured in terms of the level of output, as in some other studies. Similarly, rather than the number of workers in the final good sector, the total labor force could be used instead. These alternative specifications would yield qualitatively similar results.
} 
With the price of the final good normalized to unity, and full depreciation of private capital, profits of firm $i$ in the final sector, $\Pi_{i, t}^{Y}$, are given by

$$
\Pi_{i, t}^{Y}=Y_{t}^{i}-\left(1+\varphi_{t}\right) \sum_{1}^{M_{t}} p_{t}^{s} x_{s, t}^{i}-w_{t}^{Y} E_{t} N_{i, t}^{Y}-\left(1+r_{t}\right) K_{t}^{P, i}
$$

where $p_{t}^{s}$ is the price of intermediate good $s, w_{t}^{Y}$ the wage rate in the final good production sector, and $r_{t}$ the rental rate of private capital. As in Schiffbauer (2007), it is also assumed that transportation costs, $\varphi_{t}$, distort the distribution of intermediate goods to producers of the final good.

Each producer maximizes profits subject to (4) with respect to private inputs, labor and capital, and demand for all intermediate goods $x_{s, t}^{i}, \forall s$, taking factor prices, $M_{t}$, and $\varphi_{t}$ as given. This yields

$$
\begin{gathered}
1+r_{t}=\alpha \frac{Y_{t}^{i}}{K_{t}^{P, i}}, \quad w_{t}^{Y}=\beta \frac{Y_{t}^{i}}{E_{t} N_{i, t}^{Y}}, \\
x_{s, t}^{i}=\left[\frac{\gamma Z_{t}^{i}}{\left(1+\varphi_{t}\right) p_{t}^{s}}\right]^{1 /(1-\eta)}, \quad s=1, \ldots M_{t},
\end{gathered}
$$

where

$$
Z_{t}^{i}=Y_{t}^{i} / \sum_{1}^{M_{t}}\left(x_{s, t}^{i}\right)^{\eta}
$$

Each firm demands the same amount of each intermediate good, equation (6) implies therefore that the aggregate demand for intermediate good $s$ is

$$
x_{s, t}=\int_{0}^{1} x_{s, t}^{i} d i=\int_{0}^{1}\left[\frac{\gamma Z_{t}^{i}}{\left(1+\varphi_{t}\right) p_{t}^{s}}\right]^{1 /(1-\eta)} d i
$$

Because all firms producing the final good are identical and their number is normalized to unity, $K_{t}^{P}=K_{t}^{P, i}$, and $Z_{t}=Z_{t}^{i}, \forall i$, and the total demand for intermediate goods is the same across firms, $x_{t}^{i}=x_{t}, \forall i$. Moreover, in a symmetric equilibrium, $x_{s, t}^{i}=x_{t}^{i}, \forall s$. Thus, $\int_{0}^{1}\left[\sum_{1}^{M_{t}}\left(x_{s, t}^{i}\right)^{\eta}\right]^{1 / \eta} d i=M_{t}^{1 / \eta} x_{t}$. Using these results, equation (4) and the constant returns to scale assumption imply that aggregate output of the final good is

$$
Y_{t}=\int_{0}^{1} Y_{t}^{i} d i=\left(N_{t}^{Y}\right)^{\beta-\varepsilon \zeta_{N}}\left(\frac{K_{t}^{I}}{K_{t}^{P}}\right)^{\varepsilon}\left(\frac{M_{t}}{K_{t}^{P}}\right)^{\gamma / \eta}\left(\frac{E_{t}}{K_{t}^{P}}\right)^{\beta} x_{t}^{\gamma}\left(K_{t}^{P}\right)^{\alpha+\gamma / \eta+\beta+\varepsilon\left(1-\zeta_{K}\right)} .
$$


To ensure steady-state growth and eliminate the (weak) scale effect associated with population, the following restrictions on the congestion parameters $\zeta_{K}$ and $\zeta_{N}$ are imposed: $\alpha+\gamma / \eta+\beta+\varepsilon\left(1-\zeta_{K}\right)=1$ and $\beta-\varepsilon \zeta_{N}=0$. By implication,

$$
Y_{t}=\left(k_{t}^{I}\right)^{\varepsilon} m_{t}^{\gamma / \eta} z_{t}^{\beta} x_{t}^{\gamma} K_{t}^{P}
$$

where $k_{t}^{I}=K_{t}^{I} / K_{t}^{P}$ is the ratio of public capital to private capital, $m_{t}=M_{t} / K_{t}^{P}$ is the (disembodied) knowledge-private capital ratio, or simply the knowledge-capital ratio, and $z_{t}=E_{t} / K_{t}^{P}$ is the human capital-private capital ratio.

Transportation costs are assumed to be a decreasing function of the public-private capital ratio:

$$
\varphi_{t}=\varphi\left(k_{t}^{I}\right)
$$

where $\varphi(0)>0, \varphi^{\prime}<0$, and $\lim _{k_{t}^{I} \rightarrow \infty} \varphi_{t}=0$. Thus, from (6) and (11), access to infrastructure affects the demand for each intermediate input both directly (through its marginal product) and indirectly (through transportation costs). ${ }^{3}$

\subsection{Production of Intermediate Goods}

Firms in the intermediate sector are monopolistically competitive. There is only one producer of each input $s$, and each of them must pay a fee to use the patent (design) of that input to R\&D producers. Production of each unit of an intermediate good $s$ requires $\theta$ units of the final good.

Once the fee involved in purchasing a patent has been paid, each intermediategood producer sets its price to maximize profits, $\Pi_{s, t}^{I}$, given the perceived total demand function for its good (which determines marginal revenue), $x_{s, t}$ :

$$
\Pi_{s, t}^{I}=\left(p_{t}^{s}-\theta\right) x_{s, t} .
$$

Substituting (8) in this expression and imposing $Z_{t}^{i}=Z_{t}, \forall i$, yields

$$
\Pi_{s, t}^{I}=\left(p_{t}^{s}-\theta\right)\left[\frac{\gamma Z_{t}}{\left(1+\varphi_{t}\right) p_{t}^{s}}\right]^{1 /(1-\eta)}
$$

\footnotetext{
${ }^{3}$ It could also be assumed that poor access to public capital hampers the adoption of new technologies by producers of the final good. Insufficient access to electricity or telecommunications, for instance, may hold back the introduction and systematic use of newly-invented technologies in the production process. By implication, improved access would exert an indirect effect not only by reducing transport costs, but also by enabling firms to adopt and exploit at a faster rate the gains from innovation, as measured by a greater variety of intermediate inputs.
} 
Maximizing this expression with respect to $p_{t}^{s}$, taking $Z_{t}$ and $\varphi_{t}$ as given, yields the optimal price as

$$
p_{t}^{s}=p_{t}=\frac{\theta}{\eta} . \forall s
$$

Substituting this result in (8) implies that the optimal quantity of each intermediate good demanded by producers of the final good is

$$
x_{s, t}=x_{t}=\left[\frac{\gamma \eta Z_{t}}{\left(1+\varphi_{t}\right)}\right]^{1 /(1-\eta)} . \quad \forall s
$$

From the definition of $Z_{t}^{i}$ in (7), in equilibrium $Z_{t}=Y_{t} / M_{t} x_{t}^{\eta}$. Substituting this expression in (14) yields

$$
x_{t}=\frac{\gamma \eta}{\left(1+\varphi_{t}\right) \theta}\left(\frac{Y_{t}}{M_{t}}\right)
$$

Substituting (13) and (15) in (12) yields the maximum profit for an intermediategood producer:

$$
\Pi_{t}^{I}=\frac{(1-\eta) \gamma}{1+\varphi_{t}}\left(\frac{Y_{t}}{M_{t}}\right)
$$

which is constant in equilibrium if $Y_{t} / M_{t}$ is constant.

For simplicity, we assume that each producer of a new intermediate good is accorded a patent only for the period during which it is bought. ${ }^{4}$ The arbitrage condition requires therefore that

$$
p_{t}^{M}=\Pi_{t}^{I}
$$

\subsection{Human Capital Accumulation}

Individual human capital, $e_{t+1}$, is produced using a combination of government spending on education per worker as well as the parent's human capital and public capital, in the latter case taking into account a congestion effect measured again in terms of the private capital stock: ${ }^{5}$

$$
e_{t+1}=\left(\frac{G_{t}^{E}}{\bar{N}}\right)^{\nu_{1}} E_{t}^{1-\nu_{1}}\left(k_{t}^{I}\right)^{\nu_{2}}
$$

where $\nu_{1} \in(0,1)$ and $\nu_{2}>0$. Because individuals are identical within a generation, a parent's human capital at $t$ is equal to the average human capital of the previous

\footnotetext{
${ }^{4}$ See Agénor and Canuto (2012) for a further discussion of this assumption.

${ }^{5}$ See Agénor $(2011,2012)$ for a review of the evidence on the impact of infrastructure on education outcomes.
} 
generation, $E_{t}$. For tractability, the learning technology is assumed to exhibit constant returns to scale in government spending and human capital. In a symmetric equilibrium, we also have $e_{t}=E_{t}{ }^{6}$

\subsection{Research and Development Sector}

Firms engaged in R\&D generate designs for new intermediate inputs, using the same technology. There is no aggregate uncertainty in the innovation process.

The production of new designs depends on the existing stock of designs, effective labor, as well as government spending on R\&D (measured in units of the final good), $G_{t}^{R}$, and access to (congested) public infrastructure:

$$
M_{t+1}-M_{t}=\left(\frac{G_{t}^{R}}{E_{t}}\right)^{\phi_{1}}\left(\frac{M_{t}}{E_{t}}\right)^{\phi_{2}}\left(k_{t}^{I}\right)^{\phi_{3}} E_{t} \frac{N_{t}^{R}}{\bar{N}}
$$

where $N_{t}^{R}$ is total employment in the R\&D sector, $\phi_{1}, \phi_{2} \in(0,1)$, and $\phi_{3}>0$. As in Romer (1990), all R\&D firms have free access to the existing stock of ideas, so that each innovation creates a positive externality for future research activities; however, this occurs with diminishing returns. In addition, it is scaled by average human capital, to account for the fact that, as general knowledge increases, the marginal benefit of an increase in the existing stock of ideas becomes less relevant to promote innovation. The population size $\bar{N}$ measures here a dilution effect, as in Dinopoulos and Thompson (2000).

Government spending on $\mathrm{R} \& \mathrm{D}$ (in the form of grants for financing lab equipment, improving research facilities, etc.) has a direct impact on the ability to discover or produce new ideas. It is scaled again by average human capital, to account for the fact that, as general knowledge increases, government spending - unless it keeps pace with the economy's available human capital stock-becomes less relevant for innovation activities. ${ }^{7}$ To ensure that the marginal benefit of an increase in human capital on innovation activity remains positive, we impose $\phi_{1}+\phi_{2}<1$. Access to public capital (such as high speed telecommunications) also has a direct, positive effect on the ability to innovate, although it is also subject to congestion, as measured by the private capital stock.

\footnotetext{
${ }^{6}$ It could be assumed that, as in McDermott (2002) and Agénor and Dinh (2015), there is a spillover effect of the stock of ideas on learning, which would make the learning technology depend on $M_{t}$ as well. However, as discussed in the next section, we do not find robust empirical evidence of the latter effect.

${ }^{7}$ For instance, with the growth of knowledge, more and more sophisticated computer and lab equipment may be needed to perform research activities.
} 
R\&D firms choose labor so as to maximize profits, $\Pi_{t}^{R}$, given the dynamics of innovation captured by (19), $N_{t}^{R} \geq 0$, and taking wages, $w_{t}^{R}$, the patent price, $p_{t}^{M}$, and the public-private capital ratio as given:

$$
\max _{N_{t}^{R}} \Pi_{t}^{R}=p_{t}^{M}\left(M_{t+1}-M_{t}\right)-w_{t}^{R} E_{t} N_{t}^{R}
$$

The first-order condition is

$$
w_{t}^{R} \geq\left\{\left(\frac{G_{t}^{R}}{E_{t}}\right)^{\phi_{1}}\left(\frac{M_{t}}{E_{t}}\right)^{\phi_{2}}\left(k_{t}^{I}\right)^{\phi_{3}}\right\} p_{t}^{M},
$$

with equality if $N_{t}^{R}>0$.

\subsection{Government}

As noted earlier, the government taxes only adult wages. It spends a total of $G_{t}^{I}$ on infrastructure investment, $G_{t}^{E}$ on education, $G_{t}^{R}$ on R\&D activities, and $G_{t}^{U}$ on other items. All its services are provided free of charge. It cannot issue bonds and must therefore run a balanced budget:

$$
G_{t}=\sum G_{t}^{h}=\tau e_{t} w_{t} \bar{N}, \quad h=E, I, R, U
$$

where $w_{t}$ is the economy-wide wage.

Shares of public spending are all assumed to be constant fractions of government revenues:

$$
G_{t}^{h}=v_{h} \tau e_{t} w_{t} \bar{N}, \quad h=E, I, R, U
$$

Combining (21) and (22) therefore yields

$$
\sum_{h} v_{h}=1
$$

Assuming full depreciation, public capital in infrastructure evolves according to

$$
K_{t+1}^{I}=G_{t}^{I}
$$

\subsection{Market-Clearing Conditions}

The asset market clearing condition requires tomorrow's private capital stock to be equal to savings in period $t$ by individuals born in $t-1$. Given that $s_{t}$ is savings per household, and that the number of adults is $\bar{N}$, we have

$$
K_{t+1}^{P}=\bar{N} s_{t}
$$


where for simplicity we assume full depreciation.

With perfect labor mobility, $w_{t}^{Y}=w_{t}^{R}$; with full employment, labor market equilibrium requires

$$
N_{t}^{R}+N_{t}^{Y}=\bar{N}
$$

Using equation (5) to substitute out for $N_{t}^{Y}$, equation (26) can be used to determine equilibrium employment in the $\mathrm{R} \& \mathrm{D}$ sector:

$$
N_{t}^{R}=\bar{N}-\beta\left(\frac{Y_{t}}{E_{t}}\right) w_{t}^{-1}
$$

\section{Balanced Growth Path and Public Policy}

A dynamic equilibrium for the model is a sequence of allocations $\left\{c_{t}^{t}, c_{t+1}^{t}, s_{t}\right\}_{t=0}^{\infty}$, physical capital stocks $\left\{K_{t}^{P}, K_{t}^{I}\right\}_{t=0}^{\infty}$, human capital stock $\left\{e_{t}\right\}_{t=0}^{\infty}$, available varieties, $\left\{M_{t}\right\}_{t=0}^{\infty}$, factor prices $\left\{w_{t}, r_{t+1}\right\}_{t=0}^{\infty}$, prices and quantities of each intermediate input $\left\{p_{t}^{s}, x_{s, t}\right\}_{t=0}^{\infty}, \forall s \in\left(1, M_{t}\right)$, a constant tax rate and public spending shares such that, given initial stocks $K_{0}^{P}, K_{0}^{I}>0$, and $M_{0}>0$,

a) individuals maximize utility subject to their intertemporal budget constraint, taking prices as given;

b) firms in the final-good sector maximize profits, choosing labor, private capital, and intermediate inputs, taking the public capital stock and input prices as given;

c) intermediate goods producers set prices so as to maximize profits, while internalizing the effect of their decisions on the perceived demand curve for their product;

d) producers of new designs in the $\mathrm{R} \& \mathrm{D}$ sector maximize profits by choosing employment, taking wages, patent prices, the initial stock of designs, as well as government spending on $\mathrm{R} \& \mathrm{D}$, as given;

e) the equilibrium price of each design extracts all profits made by the corresponding intermediate good producer;

$f$ ) the government budget is balanced; and

g) all markets clear.

A balanced growth equilibrium is a dynamic equilibrium in which

a) $c_{t}^{t}, c_{t+1}^{t}, s_{t}, e_{t}, K_{t}^{P}, K_{t}^{I}, Y_{t}, M_{t}$, grow at the constant, endogenous rate $\gamma$, implying that the human capital-private capital ratio, as well as the public-private capital ratio, are also constant;

$b$ ) the rate of return on private capital $r_{t}$ and the economy-wide wage rate $w_{t}$ are constant;

c) the price of each intermediate good $p_{t}$ and the patent price $p_{t}^{M}$ are constant; and 
d) the fractions of the adult labor force engaged in the production of the final good and ideas, $n_{t}^{h}=N_{t}^{h} / \bar{N}$, with $h=R, Y$, are constant and $n_{t}^{R}+n_{t}^{Y}=1$.

The balanced growth rate of the economy is derived in Appendix A. The publicprivate capital ratio, $k_{t}^{I}$, is constant over time:

$$
k_{t}^{I}=\frac{v_{I} \tau}{\sigma(1-\tau)}=J, \quad \forall t
$$

where $\sigma \in(0,1)$ is the savings rate, defined as

$$
\sigma=\frac{1}{1+\eta_{C}(1+\rho)}<1
$$

As also shown in Appendix A, the model can be condensed into a nonlinear, first-order difference equation system in $m_{t}=M_{t} / K_{t}^{P}$, and $z_{t}=E_{t} / K_{t}^{P}$. With a used to denote steady-state values, the long-run growth rate of output per worker is given by

$$
\gamma=\Gamma(J) \tilde{m}^{\Psi} \tilde{z}^{\Omega}-1
$$

where $\tilde{m}, \tilde{z}, \Gamma(J)$, with $\Gamma^{\prime}>0, \Psi>0$ and $\Omega \gtrless 0$ are given in Appendix A.

Equation (30) illustrates the multi-dimensional effect of infrastructure on economic growth. These effects are illustrated both directly, through higher output productivity, and indirectly, through the capacity to innovate, the ability to produce human capital, and the lower transportation costs of intermediate goods. Therefore, equation (30) reveals the general equilibrium effects of infrastructure, which are likely to exceed the direct (Barro-type) productivity effects. Based on this observation, we perform two types of analyses: first, we calibrate the model and perform a policy experiment involving changes in investment in infrastructure, and second we empirically estimate the total, or general equilibrium, effect of infrastructure on growth with the use of appropriate estimation techniques.

\section{Calibration and Policy Experiment}

To illustrate the functioning of the model and examine the impact of infrastructure investment, the model is calibrated as follows. The annual discount rate is set at 0.04 , a fairly conventional choice. Interpreting a period in the OLG model as corresponding to 25 years yields the intergenerational discount factor as $[1 /(1+0.04)]^{25}=0.375$. The family's propensity to save, $\sigma=1 /\left[1+\eta_{C}(1+\rho)\right]$, is set at 0.12 , which corresponds to the value reported in Agénor and Dinh (2015). Solving (29) backward for 
the preference parameter $\eta_{C}$ yields that $\eta_{C}=\left(\sigma^{-1}-1\right) /(1+\rho)$. Given that the intergenerational discount factor is equal to 0.375 , the parameter $\eta_{C}$ is thus calibrated to obtain that value, so that $\eta_{C}=2.75$.

The elasticities of production of final goods with respect to public capital, private capital, and effective labor, $\varepsilon, \alpha$, and $\beta$ are set equal to $0.17,0.15$, and 0.65 , respectively. The value of $\varepsilon$ is the average value reported in the empirical review of Bom and Ligthart (2014, Table 4) for core public capital at the national level, whereas the value of $\beta$ is consistent with the average share of labor income for developing countries (see Agénor and Dinh (2015)). These estimates for $\alpha$ and $\beta$ imply an elasticity with respect to intermediate inputs equal to $\gamma=1-\alpha-\beta=0.2$. Transportation costs, as defined in (11), are assumed to take the form $\varphi()=\varphi_{0}\left(\tilde{k}^{I}\right)^{-\varphi_{1}}$, where $\varphi_{1} \in(0,1)$. The parameter $\varphi_{0}$ is determined in such a way that $\varphi$ is equal to 0.2 initially, that is, that transportation costs translate into higher wage costs of the order of 20 percent. Initially we set $\varphi_{1}=0.0$ (with sensitivity analysis reported later on) so we also have $\varphi_{0}=0.2$.

The parameter $\eta$, which determines the elasticity of substitution between intermediate goods, is set equal to 0.25, a fairly low value (compared to Chen and Funke (2013) for instance) to capture the case of a developing economy. The number of units of the final good needed to produce each unit of an intermediate good, $\theta$, is normalized to unity.

In the human capital sector, the elasticity of flow output with respect to government spending on education services, $\nu_{1}$, is set equal to 0.3 . This implies that the elasticity with respect to the current stock of human capital is initially equal to 0.7 . The elasticity with respect to the public-private capital ratio, $\nu_{2}$, is set equal to 0.2 initially, which is close to the value in Agénor (2011).

In the $R \& D$ sector, the elasticity with respect to government spending, $\phi_{1}$, is set equal to 0.3 , whereas the elasticity with respect to the existing stock of ideas, $\phi_{2}$, is set equal to a relatively high value, 0.7 , to capture the importance of past research for current research. The elasticity with respect to the public-private capital ratio, $\phi_{3}$, is taken to be initially 0.0 and sensitivity analysis is also reported later on.

Regarding the government, the effective tax rate on wages, $\tau$, is calculated by dividing the average ratio of tax revenues to GDP for developing countries estimated by Baldacci et al. (2004, Table1), equal to 15.1 percent for the period 2001-08, by the average share of labor income in final output, $\beta=0.65$, to match the model's definition. Thus, the effective tax rate is $\tau=23.2$ percent. The initial share of government investment on infrastructure, $v_{I}$, is set initially at 6.1 percent, whereas the initial share of government spending on education, $v_{E}$, is set at 17.1 percent, as in Agénor and Alpaslan (2013). The initial share of government investment in the 
R\&D sector, $v_{R}$, is set at a fairly low value initially, 0.05. Based on these values, (28) implies that the public-private capital ratio (which is constant over time) is $J=0.154$.

The calibrated parameters are summarized in Table 1 . Using these values the steady-state solution of the model is solved numerically, with a constant growth rate (as per the definition of the balanced growth equilibrium given earlier) for $K_{t}^{P}, K_{t}^{I}$, $E_{t}, M_{t}$, and $Y_{t}$, normalized to 3.3 percent per annum.

The main experiment that we consider here is a permanent, budget-neutral increase in the share of public expenditure on infrastructure investment, $v_{I}$, from an initial value of 0.061 to 0.081 , under three alternative assumptions: first, financed by a cut in unproductive spending $\left(d v_{I}+d v_{U}=0\right)$; second, financed by a cut in spending on education $\left(d v_{I}+d v_{E}=0\right)$; and third, financed by a cut in spending on $\mathrm{R} \& \mathrm{D}\left(d v_{I}+d v_{R}=0\right)$. In the benchmark case, infrastructure exerts two types of externalities, the first associated with productivity of private inputs in the production of final goods $(\varepsilon>0)$, as is standard in the literature, and the second associated with human capital accumulation $\left(\nu_{2}>0\right)$; there are no externalities associated with transportation costs or $\mathrm{R} \& \mathrm{D}$ activity $\left(\varphi_{1}=\phi_{3}=0\right)$. Sensitivity analysis where these two parameters take positive values is then conducted. We also consider the case where the parameter that captures the externality of public capital in terms of human capital, $\nu_{2}$, accumulation is higher than the benchmark value of 0.2 .

The steady-state results are shown in Table 2. In all cases, the increase in $v_{I}$ raises the public-private capital ratio by about 2.5 percentage points. The human capital-technical knowledge ratio also increases, particularly so when $\nu_{2}$ is high. In the benchmark case, growth increases by 0.4 percentage points when financed by a cut in unproductive spending; it also increases when financed by a reduction in productive spending, albeit by a lower amount ( 0.2 and 0.1 percentage points with a cut in education and R\&D spending, respectively). When the externalities generated by public capital in terms of either transportation costs or R\&D activity are positive (that is, either with $\varphi_{1}=0.4$ or $\phi_{3}=0.15$ in the table), or in terms of human capital accumulation $\left(\nu_{2}=0.6\right)$, the growth effect is magnified-regardless of the financing source. Thus, an increase in the share of public expenditure on infrastructure investment promotes growth, despite a concomitant reduction in other productive components of public spending, namely, subsidies to R\&D and spending on education. The externalities that public capital generates in terms of transportation costs, human capital, or innovation matter significantly not only on their ownas shown in the experiments where higher investment is financed by an offsetting cut in unproductive spending - but also because they help to mitigate the trade-offs that policymakers face when adjusting the composition of productive components of 
public expenditure.

Before proceeding to estimation, it should be noted that the effect of infrastructure on growth may also operate in a nonlinear fashion. Indeed, as noted in the introduction, several contributions have highlighted the possibility that there may be "critical mass" effects or "network externalities" associated with infrastructure. These effects imply that the benefits of infrastructure vary with the level of infrastructure itself. Specifically, this could be captured here by assuming that the elasticities $\varepsilon, \nu_{2}$, and $\phi_{3}$ appearing in equations (4), (18), and (19), respectively, may change from a relatively low (and possibly insignificant value empirically) to a relatively large (and empirically significant) value, once the stock of infrastructure (scaled by either private capital, as in the model, or by population or production) is sufficiently high. It may be, for instance, that a telecommunications network must be sufficiently developed to promote interactions between researchers and foster innovation. Moreover, there could be multiple thresholds, with a corresponding range of elasticities. In such cases, the analysis of the growth effects of infrastructure would naturally need to account also for initial conditions and possible shifts in parameters.

Because of these ambiguities, it is important to examine also empirically the link between innovation, human capital, infrastructure, and growth, while accounting explicitly for the government budget constraint - together with possible nonlinearities in the effects of infrastructure on the production of goods, human capital, and ideas. We seek to do this in the remainder of the paper.

\section{Empirical Evidence}

We now turn to an evaluation of the inter-relationship between the stock of public capital, human capital, innovation and per capita output growth while controlling for the effects of public spending on infrastructure, education, and R\&D. This empirical evaluation offers a link to our theoretical structural model as it allows us to map the coefficient estimates to some key elasticities of the model, such as the elasticities of final goods, human capital and innovation outputs with respect to infrastructure. In addition, the empirical analysis allows us to derive estimates of both the direct and the general equilibrium effects of public capital on economic growth and on the steady-state level of output. We first describe our estimation methodology and present next some basic (linear) results. To assess the robustness of these results, we then conduct a wide range of sensitivity tests. 


\subsection{Estimation Methodology}

The empirical analysis focuses on the growth effects of education, innovation, and of the level of access to infrastructure. Consistent with our theoretical framework, we take into account both the direct and indirect effects of these variables on growth. We do this by employing an empirical specification that estimates four equations, one for each of these key variables. These equations are estimated both in reduced form, independently of each other, and jointly as a system. The latter technique, by considering the simultaneous determination of the key variables, allows us to capture their main interactions alluded to earlier. In particular, the specification allows public capital to influence human capital, while at the same time capturing and identifying innovation as an important mechanism through which human capital, public capital, and public subsidies to R\&D promote economic growth. This, in turn, allows for the estimation of the general equilibrium effect of the stock of infrastructure on economic growth.

One of the main channels of influence is represented by the active role of government in the sectors of education, innovation, and infrastructure through the allocation of public resources. This means that the impact of these policies on growth is transmitted through their effects on education, innovation, and infrastructure outcomes, respectively. Our empirical strategy allows for these indirect effects by imposing the government budget constraint in the (public and human) capital and innovation equations so as to treat the impact of some components of public spending (infrastructure, education, and R\&D subsidies) in a consistent way and control for their financing method.

As pointed out in a number of recent studies (see for instance Kneller et al. (1999), Adam and Bevan (2005), and Bose et al. (2007)), one needs to acknowledge that the elements of the government budget constraint are bound together through an identity, so that all but one need to be included in a regression in order to control for both the financing element and to avoid perfect multi-collinearity. If the variables of the budget constraint are expressed as fractions of GDP, the analysis considers the level effects of fiscal instruments. It is possible, however, to also test for the composition effects of public spending by expressing the expenditure elements as fractions of total public expenditure (see Devarajan et al. (1996)). ${ }^{8}$ In both cases of composition and level effects, the coefficients on the remaining fiscal variables are understood as measuring these effects net of the effect of the excluded variable.

Given the above, our benchmark empirical setup, which dwells on our theoret-

\footnotetext{
${ }^{8}$ As before, this necessitates the exclusion of one expenditure element while also requiring to control for the level effect of total expenditure.
} 
ical model and is in line with the empirical literature in each individual area, is represented by

$$
\begin{aligned}
& g_{i t}=\alpha_{0}+\alpha_{1}{i n i t G D P_{i t}}+\alpha_{2} \text { innov }_{i t}+\alpha_{3} i n f r a_{i t}+\alpha_{4} e d u c_{i t} \\
& +\sum_{k=1}^{m} \zeta_{k} X_{k, i t}+\mu_{i}+\varepsilon_{i t} \\
& \text { innov }_{i t}=\beta_{0}+\beta_{1} \text { initGDP }_{i t}+\beta_{2} \text { infra }_{i t}+\beta_{3} \text { educ }_{i t}+\beta_{4} \text { patstock }_{i t} \\
& +\sum_{l=1}^{n-1} \lambda_{l} Z_{l, i t}+\mu_{i}+u_{i t} \\
& e d u c_{i t}=\gamma_{0}+\gamma_{1} \text { initGDP }_{i t}+\gamma_{2} \text { infra }_{i t}+\gamma_{3} \text { patstock }_{i t} \\
& +\sum_{l=1}^{n-1} \lambda_{l} Z_{l, i t}+\sum_{j=1}^{q} \theta_{j} W_{j, i t}+\mu_{i}+v_{i t} \\
& \text { infra }_{i t}=\delta_{0}+\delta_{1} \text { initGDP }_{i t}+\delta_{2} \text { urban }_{i t}+\delta_{3} \text { popdens }_{i t}+\sum_{l=1}^{n-1} \lambda_{l} Z_{l, i t}+\mu_{i}+z_{i t},
\end{aligned}
$$

where the notation is as follows: $i(t)$ is the country (time) index; $g_{i t}$ denotes the growth rate of per capita real GDP; initGDP $P_{i t}$ denotes the logarithm of initial per capita GDP; innov $_{i t}$ represents innovation output, which is traditionally measured by the total number of patent applications in logarithmic form; ${ }^{9} e d u c_{i t}$ represents education; in fra $a_{i t}$ denotes a measure of the stock of infrastructure (originally) in the telecommunications sector, proxied by the logarithm of the number of telephone lines; patstock $_{i t}$ is the stock of "technical" knowledge generated, proxied by the logarithmic stock of a country's patents. ${ }^{10}$ Following Akcomak and ter Weel (2009), we measure innovation with the number of patent applications filed to the European Patent Office (EPO) while education is measured by the share of tertiary level students in the total number of students, as primary and secondary education measures are not expected to matter significantly for innovation capacity. We use a measure of access

\footnotetext{
${ }^{9}$ Patents have been described by some as an imperfect proxy of innovation, as they may not capture the whole range of innovation, or may have dissimilar "contents of ideas," with some patents containing many (or big) ideas and other relatively few (or less relevant) ideas (Pavitt (1982)). However, they are the only well-established source that reflects innovative activity (Trajtenberg (1990)). See Bottazi and Peri (2005) and Griliches (1990) for arguments in favor of the use of patents as a measure of innovation performance.

${ }^{10}$ See Table B1 in Appendix B for details on the construction of this measure as well as a description of all the variables involved in the empirical analysis.
} 
to telecommunications as our benchmark measure of infrastructure, as it has been found in several formal studies to be the main contributive infrastructure category to economic growth (see Bougheas et al. (2000), Röller and Waverman (2001), Esfahani and Ramirez (2003), Egert et al. (2009), and Kellenberg (2009)) and in less formal studies as an important determinant of innovation activity. ${ }^{11}$ Later we test the validity of our benchmark findings to the use of different types of infrastructure. ${ }^{12}$

Variables $\left\{X_{k, i t}\right\}_{k=1}^{m}$ represent a set of conditioning variables that have been identified in growth studies to explain a substantial variation in the data. These include the rates of fertility and inflation, trade openness, and private investment. $\left\{Z_{l, i t}\right\}_{l=1}^{n-1}$ represents the set of fiscal variables in levels, measured as fractions of GDP. As explained earlier, the government budget identity in levels, $\sum_{l=1}^{n} Z_{l}=0$, requires the exclusion of one fiscal factor $Z_{0}$ so that the coefficient $\lambda_{l}=z_{l}-z_{0}$, where $z_{l}$ is the coefficient of variable $Z_{l}$, with $z_{0}$ unobserved, measures the marginal impact of the included factor $Z_{l}$, net of the marginal impact of the excluded factor $Z_{0}$. The set $\left\{Z_{l, i t}\right\}_{l=1}^{n-1}$ comprises public spending on infrastructure, education, R\&D, the remaining component of government spending, the budget deficit, and non-tax revenue; for consistency with the theoretical model, the excluded fiscal factor $Z_{0}$ is thus tax revenue. ${ }^{13}$ The set $\left\{W_{j, i t}\right\}_{j=1}^{q}$ includes a group of controls typically associated with educational attainment (life expectancy, population, and the rate of urbanization), while popdens $s_{i t}$ stands for the rate of population density. Finally, $\mu_{i}$ captures timeinvariant country-specific effects, whereas $\varepsilon_{i t}, u_{i t}, v_{i t}$, and $z_{i t}$ are the error terms.

The specification of the regression equations is based on the following considerations. Equations (31), (32), and (33) are the empirical counterparts to our structural specifications (30), (19) and (18). ${ }^{14}$ The infrastructure equation (34) is also related to our theoretical model, and captures the direct link between stocks of infrastructure assets and government spending, as shown in equation (24). The introduction of the level of initial per capita GDP in equation (31) captures conditional convergence effects and, as shown below, allows for the derivation of the elasticity of the

\footnotetext{
${ }^{11}$ See, for instance, the index of innovation capacity developed by The Economist Intelligence Unit, and the Global Innovation Index developed by INSEAD and the Confederation of Indian Industries.

${ }^{12}$ The infrastructure variables are typically measured in terms of density (that is, telephone lines per capita, electricity production per capita, roads and railtracks in kilometres of length per capita). As Egert et al. (2009) point out, however, even if such consideration sounds meaningful for some types of infrastructure, the inclusion of fixed effects in the estimation allows the use of the raw level of infrastructure in the regression. For this reason, we measure infrastructure stocks in raw levels. Robustness tests reveal that results are insensitive to the use of measures that account for density.

${ }^{13}$ At a later stage, we also test for the composition effects of public spending.

${ }^{14}$ In the education equation (33), we added the stock of patents to test for possible externalities in terms of human capital accumulation (as suggested by McDermott (2002)).
} 
steady-state level of output per capita with respect to the stock of infrastructure. ${ }^{15}$ In addition, the use of GDP level in equations (32)-(34) controls for the initial level of development.

The coefficients of interest are $\alpha_{2}, \alpha_{3}$, and $\alpha_{4}$, as they reflect the growth impact of innovation, public capital, and human capital, respectively. We also pay attention to the inter-related effects of innovation, infrastructure, and education, captured through the coefficients $\beta_{2}, \beta_{3}$, and $\gamma_{2}$. Finally, we are interested in the effect of $\mathrm{R} \& \mathrm{D}$ subsidies on innovation as these materialize through the coefficient $\lambda_{R \& D}$ in equation (32). These coefficient estimates shed light on the importance of the stock of infrastructure, educational attainment and innovative practices for growth but also for fostering one another. At the same time, they allow an identification of the growth-promoting categories of public expenditure through the above transmission channels.

The coefficient estimates serve another purpose. They provide a link with our theoretical model as they can be used to derive the elasticities of human capital and innovation outputs with respect to their inputs, and in particular the stock of infrastructure (i.e., $\nu_{1}, \nu_{2}, \phi_{1}, \phi_{2}$, and $\phi_{3}$ ). Furthermore, as described below, the GDP growth rate equation (31) allows us to calculate the elasticity of the steady-state level of per capita output with respect to infrastructure. In this way, our empirical analysis pins down the magnitude of some key elasticity parameters with a variety of estimation techniques, which as described below, can distinguish between direct and general equilibrium effects.

Even though the message of our theoretical model points toward an estimation technique where the main endogenous variables are jointly determined, we conduct our analysis both with single- and multiple-equation techniques. The reasoning is that the equation-by-equation estimation exercise provides the direct effects of the explanatory variables on the response variables. The simultaneous equations system, by contrast, provides both the direct and indirect, or general equilibrium, effects. Therefore, comparison between the estimates obtained by the two techniques gives an indication of the degree to which the two types of effects (direct vs. total) differ. This, in turn, may reflect the importance one needs to attach to the estimation of a structural model that takes into account general equilibrium effects. For instance, in terms of our theoretical model equation (30), estimation of the effect of infrastructure on GDP per capita growth (in equation (31)) as a single equation does not account for the fact that $\tilde{m}$ and $\tilde{z}$ adjust due to a change in the stock of infrastructure.

\footnotetext{
${ }^{15}$ Even though our theoretical analysis has focused on a balanced growth path in which transitional dynamics are ignored, the empirical counterpart of equation (30) accounts for conditional convergence to avoid the possibility of ommitted variable bias.
} 
The system regression, by contrast, does account for the possibility that both $\tilde{k}^{P}$ and $\tilde{z}$ may fluctuate in response to a change in the stock of infrastructure. ${ }^{16}$ It is, therefore, useful to use both regression techniques (single vs. multiple) and compare their outcomes. ${ }^{17}$

We use three econometric procedures to estimate equations (31)-(34). The first is a standard panel regression technique controlling for unobserved country-specific effects using the fixed effects estimator. The remaining two estimation procedures, that also control for country-fixed effects, are based on techniques that address potential endogeneity of the right-hand-side variables. The first is a dynamic GMM estimation and the second is a 3SLS joint estimation of equations (31)-(34).

The dynamic estimation procedure corresponds to the difference-GMM estimator developed by Arellano and Bond (1991). A consideration associated with this estimator relates to the choice of the number of lags of the endogenous variables used as instruments. As Roodman (2009) points out, an excessive number of instruments can result in overfitting of the instrumented variables, thereby biasing the results towards those obtained by OLS. As a rule of thumb, the number of instruments is suggested not to exceed the number of countries. Typically, the way these problems are minimized is by subjecting the empirical model to sensitivity tests, with various sets of lags in line with the above restriction on the number of instruments. ${ }^{18}$

The GMM approach we use is checked for the validity of instruments by applying three specification tests. The first is the Hansen (1982) J-test of over-identifying restrictions, which we use to examine the exogeneity of the instruments. To avoid dynamic panel bias we instrument for regressors that are not strictly exogenous - this means all of the control variables in equations (31)-(34). The second, also applied in the 3SLS regressions, is the weak instrument first-stage F-test for the statistical significance of the instruments. As a rule of thumb, a value below 10 suggests weak instruments (Stock and Yogo, 2005). The third test is the Arellano and Bond (1991)

\footnotetext{
${ }^{16}$ See expressions (A21) and (A22) in Appendix A.

${ }^{17}$ Note that neither of the two regression techniques can isolate the productivity effect of infrastructure on economic growth. As the term $\Psi$ of equation (30) reveals, the coefficient estimate of infrastructure in the growth regression represents a composite of the productivity effect $(\varepsilon)$, the effect on costs of transportation (through $\varphi$ ), and the elasticities of education and innovation with respect to infrastructure $\left(\phi_{3}\right.$ and $\left.\nu_{2}\right)$. The single-estimation technique estimates exactly this composite effect, while the simultaneous equations method estimates this composite effect along with the indirect effect that arises through changes in $\tilde{k}^{P}$ and $\tilde{z}$. The latter represents the total effect, which is expected to exceed the direct effect in magnitude.

${ }^{18}$ The counterpart of difference-GMM, the system-GMM estimator of Blundell and Bond (1998), is not utilised in the current study. The reason is that with this technique the number of instruments always exceeds by far the number of countries in our sample. This is due to the limited availability of $\mathrm{R} \& \mathrm{D}$ data.
} 
test for serial correlation, the existence of which can cause bias to both the estimated coefficients and standard errors.

\subsection{Data}

Our data span 38 countries (a list of which is given in Appendix B) for the period 1981-2008. The choice of both the sample of countries and of the time period is restricted by the availability of data on public R\&D expenditure as these are available for a long time series only for the OECD members (30) and affiliate countries (8). As our analysis entails growth regressions, we follow the standard approach of constructing 4-year period averages $(1981-84,1985-88,1989-92, \ldots, 2005-08)$ so as to minimize business cycle effects. This implies a maximum sample size of $266 \mathrm{ob}-$ servations, although we end up working with an unbalanced panel of as few as 124 observations for the innovation equation due to missing data. As Table B1 illustrates, our data are drawn from a variety of sources that include the World Development Indicators (World Bank), Government Finance Statistics (IMF), Main Science and Technology Indicators (OECD), and UNESCO. Table 3 presents summary statistics of the variables used in the benchmark model of equations (31)-(34).

\subsection{Benchmark Results}

We begin our investigation by estimating equations (31)-(34) independently of each other with fixed-effects and difference-GMM. Then, we allow for a simultaneous estimation of all four equations with 3SLS. Recall that according to the theoretical mechanisms of the preceding section, the key variables of education and infrastructure may influence growth both directly and indirectly, while innovation operates only directly. In addition, the growth effect of public spending on R\&D takes shape through innovation. Our benchmark findings are presented in Table 4.

We start with the stock of infrastructure equation (34), estimated with fixed effects, that appears in the set of columns (1). The stock of infrastructure is positively associated with the level of a country's development and the degree of urbanization, and negatively by the fiscal variables of infrastructure expenditure and the budget balance. At the same time, the remaining component (net of infrastructure) of public expenditure, the non-tax revenue, and the density of the population, do not seem to matter. As regards the effects of the fiscal variables, recall that we omit the category of tax revenue pertaining to the level effects of these variables, as a way of avoiding collinearity problems. Our results suggest that the marginal impact of public infrastructure spending on the stock of infrastructure when financed by tax 
revenue is significantly negative, while the marginal effect of the rest of government expenditure is not statistically significant. On the revenue side, the marginal impact of increased government borrowing is significantly negative (at the 10 percent level), whilst the marginal impact of raising revenue from non-tax sources is not significantly different from zero.

The negative effect of infrastructure spending on the stock of infrastructure, which is of interest from the perspective of fiscal policy, hinges on three assumptions. First, it depends on the way infrastructure spending is financed. Second, because we do not control for potential endogeneity of infrastructure spending, the negative effect may reflect the lower commitment of governments to spend toward infrastructure in countries with a high infrastructure stock. Third, the effect may reflect the disassociation between infrastructure flows and stocks, as public infrastructure spending may not fully materialize into stock due to corrupt practices and public sector inefficiencies (see Agénor (2010)).

Turning to the education equation, greater life expectancy and a higher stock of infrastructure have a positive impact on education, while the rate of urbanization and the population size have a negative effect. The rest of the variables (level of development, marginal effect of fiscal variables, and stock of patents) have no explanatory power. The variables that appear to significantly influence education are in line with the findings of the related literature (see, for instance, Gupta et al. (1999)), while the sizable and highly significant positive effect of infrastructure stock supports our theoretical modelling.

Moving to the innovation equation, we observe strong positive effects of public $R \& D$ expenditure, the stock of infrastructure, the stock of patents, and of education on innovation capacity. These findings support the importance of infrastructure and education, as well as the use of R\&D expenditure by the government, as a way of boosting innovation activity, not only directly but also through the accumulation of the stock of patents. These findings are in line with Prodan (2005), Ulku (2007a, 2007b), and Akcomak and ter Weel (2009) regarding the contribution of R\&D intensity, measured either as public subsidies or as the share of R\&D personnel employment in total employment. To our knowledge, however, no study has examined thus far the effect of infrastructure on innovation activity. ${ }^{19}$

Finally, the estimation of the growth equation is supportive of the general findings in the literature as to the significance of income convergence effects and the growthpromoting impacts of higher levels of private investment and of a more outward-

\footnotetext{
${ }^{19}$ Schiffbauer (2007) examined the effect of telecommunications infrastructure on the total public R\&D expenditure (as a share of GDP). The latter, however, being a measure of innovation input, does not reflect innovation performance.
} 
oriented trade policy. The results also reveal the strong influence of the key variables of our model on growth. The stock of infrastructure, the level of innovation, and the degree of educational attainment are all directly conducive to faster economic growth. If one also takes into account the indirect effects of these variables, as described above, then the positive impact of these key variables on growth is likely to be greater in magnitude. This is where one of our main contributions lies; although a number of studies in the literature have found that infrastructure is growth-enhancing (see Bougheas et al. (2000), Röller and Waverman (2001), Esfahani and Ramirez (2003), Calderón and Servén (2004), Straub (2008), and Egert et al. (2009)), none of them has accounted for the indirect channels outlined here. Overall, the empirical findings offer support to the assumptions of our theoretical model, in particular with regard to the production process of human capital and new designs.

One possible drawback of the results presented thus far is that they may be biased by the endogeneity of some of the regressors. To overcome such a problem, the following two sets of columns present results that control for reverse causality. Column set (2) illustrates the difference-GMM regression, whereas set (3) presents the results of the 3SLS regression with the instrumented variables appearing in bold type. In both of them, we observe the following consistent findings: a) a positive impact of public R\&D subsidies on innovation activity; $b$ ) a positive effect of the stock of infrastructure on education outcomes, innovation activity, and economic growth; c) a positive impact of education on innovation; $d$ ) a positive effect of patents stock on innovation; and $e$ ) an enhancing effect of innovation capacity on economic growth. The effect of education on growth is not significant in the GMM estimation and is found to have a negative effect in the 3SLS results, while the inflation rate picks up a negative sign under both estimation methods. ${ }^{20}$ In addition, and in contrast to the results of the fixed-effects estimation, proper instrumentation of the government expenditure share to infrastructure unveils a statistically zero effect on the stock of infrastructure. $^{21}$

\footnotetext{
${ }^{20}$ The insignificant growth effect of education is quite common in the growth literature across both heterogeneous country samples (Bose et al. (2007)) and homogeneous samples (Akcomak and ter Weel (2009) and Kneller et al. (1999)). The negative effect unveiled under 3SLS can be due to the distorted structural composition of the labor force in developing countries, especially with regard to highly-educated individuals, and the inefficient allocation of talent across sectors.

${ }^{21}$ The instruments used in the difference-GMM regression are the second-to-fifth lags of the instrumented variables (second and third for the education regression) using the 'collapse' option in STATA to create one instrument for each variable and lag distance, rather than one instrument for each time period, variable, and lag distance. This allows for a smaller number of instruments, even compared to the use of only the second lag as instrument for each one of the regressions. The latter, however, produces results equivalent to those reported.
} 
Hansen's $J$-statistic, which examines the validity of the instruments in the GMM estimation, is also reported in Table 4. These specification tests cannot reject the hypothesis that the instruments are uncorrelated with the error term at a standard confidence level. In addition, the Arellano-Bond (1991) test rejects the hypothesis of no second-order serial correlation in the error term in all, but the education, regressions at any conventional level of significance. Finally, the weak identification F-test statistic suggests the rejection of the null hypothesis of weak instruments for all GMM and 3SLS regressions.

As discussed earlier, the coefficient estimates reported in Table 4 are not only interesting for their qualitative impact (that is, the sign of the effect of the controlled variables), but also for their quantitative implications. First, the estimates can be used to calculate some key elasticity parameters that map into our theoretical model. Second, any differences in these elasticities across the single- and the multipleregression estimations can be viewed as capturing the wedge between the direct and the general equilibrium effects. In what follows, we focus our attention on the elasticity parameters of the human capital accumulation equation $(18),\left(\nu_{1}, \nu_{2}\right)$, and of the new designs production equation (19), $\left(\phi_{1}, \phi_{2}, \phi_{3}\right)$. Moreover, we obtain estimates of the long-run elasticity of the level of economic output per capita with respect to the stock of infrastructure.

Some of the coefficient estimates in Table 4 represent elasticities as both the dependent and the explanatory variables enter in logarithmic forms. This is true for the stock of patents and the stock of infrastructure in the innovation equation (32). Therefore, the coefficient estimates $\hat{\beta}_{2}$ and $\hat{\beta}_{4}$ correspond to the elasticity parameters $\phi_{3}$ and $\phi_{2}$ in our theoretical model. ${ }^{22}$ The remaining elasticities are obtained with some further manipulation. Specifically,

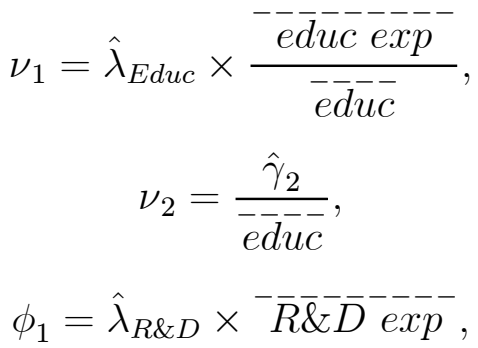

Output elasticity of infrastructure steady-state $=-\frac{\hat{\alpha}_{3}}{\hat{\alpha}_{1}}$,

\footnotetext{
${ }^{22} \mathrm{~A}$ hat above a parameter denotes the coefficient estimate of that parameter.
} 
where educ exp denotes education expenditure as fraction of GDP, $R \& D$ exp stands for R\&D expenditure as fraction of GDP, and a bar above a variable indicates its mean value. Note that, following Angeles and Neanidis (2009), we use the implicit function theorem to obtain a measure of the elasticity of per capita output with respect to the stock of infrastructure at the steady state by dividing the coefficient estimate of infrastructure stock in the growth regression, $\hat{\alpha}_{3}$, by the negative of the coefficient estimate of GDP per capita in the same regression, $\hat{\alpha}_{1}$.

Table 5 presents these elasticity parameters by using the coefficient estimates reported in Table 4, assigning a dash when a coefficient estimate is not statistically significant. The first thing to notice is that the elasticities are quite sizeable even for the single-equation estimation methods. The stock of infrastructure has a sizeable influence on both the accumulation of human capital and the production of innovative output as the respective elasticities are in the areas of $0.6-0.7$ and $0.2-0.3$. The first range of values is substantially higher than the parameter values used by Chen (2005) and Agénor (2011), while the second range is about half the size of the econometric estimate obtained by Sokoloff (1988).

Equally sizeable are the elasticities of innovative output with respect to public spending on R\&D and to prior innovative contributions, as measured by the stock of knowledge. The values for these two elasticities lie between $0.2-0.3$ and $0.4-0.7$ respectively. Ulku (2007a) estimates elasticities of comparable magnitude $(0.2$ and 0.5 respectively) in a sub-sample of 26 OECD countries with a large market (defined as having aggregate GDP above the sample median value).

Particular attention is reserved for the output elasticity of infrastructure which lies in the range of 0.1-0.2. These values are consistent with other findings in the literature, such as Röller and Waverman (2001) who find an elasticity of 0.15 for 21 OECD countries over 1970-1990, Shioji (2001) that estimates a long-run elasticity of 0.1-0.15 for US states and Japanese prefectures over four decades (1960s-1990s), Esfahani and Ramirez (2003) who find an elasticity of 0.1 for a panel of 75 countries over the period 1965-1995, and Kamps (2006) that estimates an average elasticity of 0.2 for 22 OECD countries over 1960-2001. It is also consistent with the average of 0.17 reported by Bom and Ligthart (2014, Table 4) for core public capital at the national level, as noted earlier.

As one moves from the single-equation regression coefficients to the simultaneous system of equations, we observe an increase in the size of every elasticity (with the exception of $\phi_{2}$ which is at about the same level as the GMM estimate). Now even $\nu_{1}$ takes up a positive value of 0.1, which is equal to the value used by Rioja (2005) and comparable to the estimates found by Gupta et al. (2002), which are in the range 
of $0.08-0.16 .^{23}$ In addition, $\phi_{3}$ now is in line with the estimate of Sokoloff (1988). The elasticity of long-run per capita output with regard to infrastructure also rises to 0.26 . This result suggests that a simultaneous equation model, which is better suited to account for indirect effects, represents a more accurate method of identifying the total effect of infrastructure. For this reason, the remaining of the analysis presents results based solely on this technique. ${ }^{24}$

\subsection{Robustness}

We examine the sensitivity of our benchmark results by re-running the regressions under various modifications. These include the use of alternative measures of innovation, various proxies for infrastructure, accounting for the quality of infrastructure, and testing for the presence of threshold effects related to infrastructure. Our basic findings survive all of these checks.

\subsubsection{Alternative Measures of Innovation}

The proxy for innovation we have used corresponds to the total number of patent applications filed to the European Patent Office (EPO) by year of filing, according to the inventor's country of residence (per million inhabitants). Even though the use of the residence of the inventor as the idea's country of origin is standard in the literature, many studies have proxied the generation of innovative ideas by the number of patent applications to the US Patent and Trademark Office (USPTO). Ulku $(2007 a, 2007 b)$ suggests that this choice is typically guided by the fact that the US attracts the highest number of international patent applications, as it has the most dynamic market for technological innovation. ${ }^{25}$ As such, US patents are thought to provide a good approximation for the rate of technological innovation of countries. In addition, Bottazi and Peri (2005) suggest a "cost-benefit" justification,

\footnotetext{
${ }^{23}$ To make the results in Gupta et al. (2002) comparable to our estimates, we calculated the elasticity $\nu_{1}$ using the same technique as described earlier. Note that their estimates are based on gross primary and secondary enrollment rates.

${ }^{24}$ The results described in this section remain unchanged if instead of using the level effects of fiscal variables, we use the composition effects. The latter are obtained by introducing fiscal variables as shares of total public expenditure, while also controlling for the level effect of total government expenditure (see Devarajan et al. (1996)). The results are available upon request.

${ }^{25}$ This is verified in our sample as the average number of total patent applications to the USPTO exceed that of the EPO by one-third. Accounting for the size of the population of the inventor's country of origin, however, reverses the order as patent applications to the EPO exceed those of the USPTO by a third. This offers indirect support for the use of the EPO filed patents as our benchmark measure.
} 
in the sense that the USPTO likely attracts the most important innovations. By this reasoning, innovations with marginal use or with a low likelihood of profitability would not be worth the patenting cost in the US.

Apart from the number of patent applications submitted to the EPO and USPTO, one more patent indicator of inventive performance relates to the number of patent applications filed under the Patent Co-operation Treaty (PCT). The PCT "makes it possible to seek patent protection for an invention simultaneously in each of a large number of countries by filling an 'international' patent application." It thus represents a more global type of recognition and protection of patents. Given the variety of patent indicators, it is prudent to examine the validity of our benchmark findings against these alternative measures.

A first indication of the high comparability of the different innovation measures is offered by the correlation coefficients of the EPO patent applications with those filed at the USPTO and PCT. For our sample these are 0.88 and 0.87 respectively, both significant at the 1 percent level. A formal evaluation of the impact of these indicators is reported in Table 6 with regard to the 3SLS estimation, where the set in columns (1) repeats the findings of the benchmark innovation measure from Table 4 for ease of comparison. The results are in general supportive of our benchmark findings. Exceptions are that, for two of the three measures of innovation, education negatively affects innovation and R\&D public spending improves innovation output. Other than these, the stock of infrastructure continues to promote education, innovation, and economic growth outcomes; the stock of patents improves innovation capacity; and innovation output has a positive effect on growth. Therefore, we can conclude that the choice of the innovation measure does not significantly impact upon the qualitative effects of the stock of infrastructure and of public R\&D spending on growth.

The last statement is supported by the evidence reported in Table 7, which shows estimated elasticity values. These values do not differ widely across the three measures of innovation, particularly so for the elasticity of long-run output with respect to infrastructure, which varies between $0.22-0.27$, while some variability is observed in the magnitude of the elasticities of $R \& D$ production, especially with respect to infrastructure.

\subsubsection{Alternative Proxies for Infrastructure}

In the foregoing analysis we have used the number of main telephone lines as our preferred measure of the stock of infrastructure, as this measure reflects the most widely used indicator in the literature (see for instance Easterly (2001), Röller and 
Waverman (2001), Loayza et al. (2004), Schiffbauer (2007), Kellenberg (2009)). At the same time, accessibility of telecommunication services seems to play a particularly important role on the ability to create new and more efficient technologies within (and across economies) as outlined in our theoretical framework. Given, however, the increasing popularity of mobile phones since the mid-1990s our current estimates may not fully capture the influence of telecommunications networks. In order to account for this, we use the total number of mobile and fixed-line telephone subscriptions. ${ }^{26}$

The literature also offers some additional indicators of infrastructure. They mostly relate to the sectors of energy and transportation, measured by the amount of energy consumption, energy production, electricity production (or generating capacity), and the length of the road and/or rail network. Some studies have even built synthetic indices of various dimensions of infrastructure by applying principal component analysis (Calderón and Servén (2004, 2009), Egert et al. (2009)). To explore the implications of the choice of the infrastructure sector for our benchmark results, we repeat our analysis by looking at a country's electricity production capacity and by building an aggregate index of infrastructure stock in line with Calderón and Servén $(2004,2009) .^{27}$

The results of these regressions are shown in Table 8. The use of the alternative infrastructure measures does not change our original conclusions in any meaningful way. The sole exception is that innovation's effect on growth turns out to be insignificant for the energy sector. Most importantly, however, the effect of the stock of infrastructure on education, innovation and growth outcomes continues to be positive and significant for both the telecommunications and the power sectors, as well as for the synthetic index of infrastructure.

The insensitivity of the findings is also illustrated in Table 9 that presents estimated elasticity values. These values do not vary largely across the three infrastructure indicators, nor do they when compared with the initial infrastructure indicator of main telephone lines. However, worthy of note is that the elasticity of steady-state output per capita with respect to infrastructure jumps to a value of 0.4 for the energy sector.

\footnotetext{
${ }^{26}$ Note though that line subscriptions are not strictly a physical measure of telecommunications infrastructure and may actually reflect an increase in use that represents congestion effects.

${ }^{27}$ The aggregate index combines information from all infrastructure measures as it corresponds to the first principle component of the number of main telephone lines (per capita), the electricity generating capacity (in kWh per capita), and the density of the road network (per sq. km. of land area). All variables are expressed in logs and the corresponding estimated eigenvectors are 0.6982, 0.6289 , and 0.3419 .
} 


\subsubsection{Infrastructure Quality}

A handful of papers go beyond measures of infrastructure stocks and consider issues of infrastructure quality and efficiency. Hulten (1996) develops an effectiveness index of infrastructure and finds a growth impact of more than seven times larger compared to that of the quantity of public capital. Esfahani and Ramirez (2003) show that the effectiveness of the stock of infrastructure on economic growth is affected by institutional factors. Calderón and Servén (2004) build a synthetic indicator of infrastructure quality and report an effect that is not significantly related to growth but does contribute to lower income inequality. More recently, Calderón (2009), using the same aggregate index of infrastructure quality, found a significant positive effect on growth for Africa.

Keeping in mind that having an operational and credible infrastructure network may be of equal importance as the physical presence of such a network, especially for the creation and distribution of new technologies, we add to our benchmark 3SLS regression indicators of infrastructure quality. These indicators are added in both the innovation and growth equations to capture the indirect and direct effects of infrastructure quality. We do this for all the infrastructure sectors we have used in the previous section (telecommunications, energy, and aggregate index) in order to examine whether the addition of the quality measures alters the impact of the quantity counterparts. Table 10 reports the results.

First, we add an indicator of quality in the services offered by the telecommunications network, measured by the number of telephone faults. ${ }^{28}$ In line with the benchmark findings, the stock of infrastructure continues to have a positive and significant impact on the education, innovation and economic growth outcomes (with innovation still contributing significantly to growth). In addition to this quantity effect now the quality of the telecom network matters also directly for growth, as the poor quality of telecommunications diminishes growth. In the set of columns (2), we add as an indicator of quality in the power sector the percentage of electricity production that is lost due to transmission and distribution problems. As in Table 8 , the quantity of electricity production is conducive to education, innovation and growth. Also, as with the telecommunication services, poor quality in the form of lost transmission and distribution of electric power has a direct negative effect on growth. The third column presents results that include synthetic indices of both infrastructure quantity and quality. ${ }^{29}$ The findings support once again the importance

\footnotetext{
${ }^{28}$ Results are the same when we use either the number of main telephone lines or the number of mobile and fixed-line subscriptions as a measure of the quantity of the telecom infrastructure. Note that the addition of the quality measure, leads to a drop of the sample size by about 40 percent.

${ }^{29}$ To generate the quality index, we follow once again Calderón and Servén $(2004,2009)$. The
} 
of the stock of infrastructure for both education and growth (but not innovation), while, at the same time, a lower quality of infrastructure reduces economic growth.

Table 11 shows the implied elasticity parameters once we control for infrastructure quality. The values are in general comparable with those of Table 9 , which ignore quality considerations. The main feature of Table 11 is the sizeable elasticity of long-run per capita output with respect to the quality of infrastructure for electricity production, which takes up a value of 0.502. This estimate exceeds its quantity counterpart and conveys information in line with the findings of Hulten (1996) as to the far greater importance of the quality of electricity power for economic performance. In general, however, these findings emphasize the dual influence of public infrastructure on growth as both the quality and the quantity of public capital are important determinants of economic performance.

\subsubsection{Infrastructure Threshold Effects}

A few studies in the infrastructure-growth literature have considered the potentially nonlinear nature of this relationship. On the theoretical side, Agénor (2010) developed a model where due to network externalities the degree of efficiency of infrastructure is increasing with the size of the public capital stock itself. An implication of such network effects is that the impact of infrastructure on growth may not be linear, but subject to threshold effects. In other words, the growth impact may be larger once a significant network size is achieved. These "critical mass" effects associated with public infrastructure have also been examined empirically. Röller and Waverman (2001) and Kellenberg (2009) examined nonlinearities related specifically to the telecommunications infrastructure. Even though they find on average a positive growth effect, the magnitude of the effect increases (doubles) in countries with high levels of telecommunications infrastructure, offering support to the presence of a critical mass at levels around universal service. In the same vein, Czernich et al. (2011) found that broadband matters for growth only above a threshold of 10 percent penetration rates. Bougheas et al. (2000) and Egert et al. (2009), on the other hand, report results that support the presence of diminishing returns on growth associated with the size of the telecommunication and transport infrastructure and telecommunication and energy infrastructure, respectively.

We take up the issue of nonlinearities in the infrastructure-growth relationship for all the measures of infrastructure stock used in the previous sections. As in the

infrastructure quality index is the first principle component of the percent of telephone faults in total telephone lines, the fraction of electricity production lost, and the percent of non-paved roads in total roads. The corresponding estimated eigenvectors are $0.4649,0.6391$, and 0.6127 . Note that all quality measures are scaled so that higher values indicate lower quality of infrastructure. 
above studies, we test for threshold effects of infrastructure in the growth equation. Moreover, we test for such nonlinearities in the innovation equation in line with our earlier discussion. This consideration allows us to check for indirect threshold effects of infrastructure on growth through innovation. ${ }^{30}$ This requires respecifying equations (31) and (32) as

$$
\begin{gathered}
g_{i t}=\alpha_{0}+\alpha_{1} \text { initGDP }_{i t}+\alpha_{2} \text { innov }_{i t}+\left(\alpha_{3}+\alpha_{4} \text { High }\right) \times \text { infra }_{i t} \\
+\alpha_{6} \text { educ }_{i t}+\sum_{k=1}^{m} \zeta_{k} X_{k, i t}+\mu_{i}+\varepsilon_{i t}, \\
\text { innov }_{i t}=\beta_{0}+\beta_{1} \text { initGDP }_{i t}+\left(\beta_{2}+\beta_{3} H i g h\right) \times \text { infra }_{i t} \\
+\beta_{5} \text { educ }_{i t}+\beta_{6} \text { patstock }_{i t}+\sum_{l=1}^{n-1} \lambda_{l} Z_{l, i t}+\mu_{i}+u_{i t},
\end{gathered}
$$

where the dummy variable High corresponds to the classification defined in Table B1. ${ }^{31}$ Given our findings of an increasing impact of infrastructure on both innovation and growth (i.e., $\beta_{2}, \alpha_{3}>0$ ), positive and significant coefficients for the interaction terms $\left(\beta_{3}\right.$ and $\left.\alpha_{4}\right)$ would support the network effects theory, whereas negative coefficients would support the diminishing returns hypothesis. Table 12 reports the findings.

For the telecommunications infrastructure (column set (1)) the results accord well with our benchmark findings. ${ }^{32}$ Moreover, they illustrate the presence of diminishing returns of infrastructure on innovation and of network effects on economic growth. The parameter estimate $\beta_{2}$ indicates that important innovation effects from telecommunications infrastructure exist, particularly for countries with a relatively low stock to begin with. The positive innovation effects diminish in magnitude for higher levels of telecommunication infrastructure $\left(\beta_{3}<0\right)$. The decline in magnitude is, however, small. ${ }^{33}$ Further, the positive and significant signs of $\alpha_{3}$ and $\alpha_{4}$ offer support to the findings of Röller and Waverman (2001) and Kellenberg (2009), both with regard

\footnotetext{
${ }^{30}$ We have also added public capital thresholds in the education equation but they have not been found to be statistically significant. As this addition has no bearing on the rest of the coefficient estimates, we chose to drop the thresholds from the education equation in favor of a more parsimonious model.

${ }^{31}$ The thresholds of the telecommunications sector follow Röller and Waverman (2001) and Kellenberg (2009). As for the energy sector and the synthetic infrastructure index, the dummy High corresponds to values that exceed the average value of our sample.

${ }^{32}$ The same is true when we use the number of mobile and fixed-line subscriptions instead.

${ }^{33} \mathrm{~A}$ joint test of the overall significance of high telecommunications countries reveals that there exists a statistically significant positive effect on innovation output at the 1 percent level.
} 
to the critical mass story and the location of the threshold. As with innovation, however, the marginal growth impact of higher infrastructure estimated at about 9 percent - is not sizeable.

The next set of columns examines the presence of nonlinear effects for the energy sector. The findings point to diminishing threshold effects on innovation $\left(\beta_{3}<0\right)$ but only linear growth effects. As with telecommunications, the size of this declining effect is marginal. Finally, the last set of columns confirms the declining threshold effects of the synthetic infrastructure index on innovation $\left(\beta_{3}<0\right)$ and the linear effects on economic growth. Turning to Table 13, we observe that the described nonlinear effects have a minor impact on the estimated elasticities, preserving the general findings reported in the absence of threshold effects.

\section{Concluding Remarks}

This paper studied interactions between public capital, human capital, and innovation in a three-period OLG model of endogenous growth. In the model, public capital was shown to affect growth not only through productivity, but also through transportation costs, the capacity to innovate, and the economy's ability to produce human capital. After deriving the steady-state growth rate of output, the model was used to illustrate the trade-offs involved in the allocation of public spending to R\&D and other productive components, namely, infrastructure and education. The implications of the model are tested using a sample of 38 developed and developing countries for the period 1981-2008 and a variety of econometric procedures, including standard panel regression techniques as well as methods that address potential endogeneity problems (dynamic GMM and 3SLS). Among other results, we found that higher innovation performance is conducive to per capita income growth while the stock of public capital has both direct and indirect growth effects, by raising the capacity to innovate and the rate of human capital accumulation. Taking proper account of the government's budget constraint, our estimates also suggest that public spending on R\&D contributes to growth by fostering innovation. We also found that the quality of infrastructure matters (in line with other studies), and that the impact of infrastructure on innovation capacity appears to be subject to threshold effects. Finally, using our coefficient estimates we obtain values for various elasticity parameters. Elasticity estimates derived from simultaneous equation techniques show that the general equilibrium effects of public capital on steady-state output per capita (which accounts for indirect effects though human capital and innovation) are - at least in our sample - significantly higher than those derived from single equation methods, as reported in recent studies. 
Our analysis has important implications for public policies aimed at fostering innovation and the design of growth-promoting public expenditure programs in general, for low- and middle-income countries. First, our theoretical framework and estimation results suggest that access to public capital can promote growth not only directly (through standard productivity effects), but also indirectly through its impact on human capital accumulation and the capacity to innovate. Moreover, the contribution of human capital to growth seems to operate mostly through its impact on innovation capacity; to the extent that access to infrastructure acts as constraint on the expansion of R\&D activities, public spending on human capital may have little impact on growth. Second, there is some evidence that for public infrastructure to have a sizable direct effect on growth, there must be enough of it for "critical mass" effects to kick in. Thus, for many low- and middle-income countries, to promote growth may require allocating sufficient government resources to boost the quantity and quality of public infrastructure, especially in telecommunications. ${ }^{34}$

\footnotetext{
${ }^{34}$ Of course, this prescription assumes that investment in infrastructure is efficient enough; see Agénor (2010) for a further discussion.
} 


\section{References}

Adam, Christopher S., and David L. Bevan, "Fiscal Deficits and Growth in Developing Countries," Journal of Public Economics, 89 (April 2005), 571-97.

Agénor, Pierre-Richard, "A Theory of Infrastructure-led Development," Journal of Economic Dynamics and Control, 34 (May 2010), 932-50.

— , "Schooling and Public Capital in a Model of Endogenous Growth," Economica, 78 (January 2011), 108-32.

—, Public Capital, Growth and Welfare, Princeton University Press (Princeton, New Jersey: 2012).

Agénor, Pierre-Richard, and Baris Alpaslan, "Child Labor, Intra-Household Bargaining and Economic Growth," Working Paper No. 181, Centre for Growth and Business Cycle Research (February 2013).

Agénor, Pierre-Richard, and Otaviano Canuto, "Middle-Income Growth Traps," Policy Research Working Paper No. 6210, World Bank (September 2012).

Agénor, Pierre-Richard, and Hinh Dinh, "Social Capital, Product Imitation and Growth with Learning Externalities," Journal of Development Economics, 114 (May 2015), 41-54.

Aghion, Philippe, and Peter Howitt, "A Model of Growth through Creative Destruction," Econometrica, 60 (March 1992), 323-51.

Akcomak, Semih, and Bas Ter Weel, "Social Capital, Innovation and Growth: Evidence from Europe," European Economic Review, 53 (July 2009), 544-67.

Angeles, Luis, and Kyriakos C. Neanidis, "Aid Effectiveness: The Role of the Local Elite," Journal of Development Economics, 90 (September 2009), 120-34.

Arnold, Lutz G., "Growth, Welfare, and Trade in an Integrated Model of Human-Capital Accumulation and Research," Journal of Macroeconomics, 29 (December 1998), 81105.

Arellano, Manuel, and Stephen Bond, "Some Tests of Specification for Panel Data: Monte Carlo Evidence and an Application to Employment Equations," Review of Economic Studies, 58 (April 1991), 277-97.

Baldacci, Emanuele, Arye L. Hillman, and Naoko C. Kojo, "Growth, Governance, and Fiscal Policy Transmission Channels in Low-Income Countries," European Journal of Political Economy, 20 (June 2004), 517-49.

Barro, Robert J., "Government Spending in a Simple Model of Endogenous Growth," Journal of Political Economy, 98 (June 1990), 103-25.

Blundel, Richard, and Stephen Bond, "Initial Conditions and Moment Restrictions in Dynamic Panel Data Models," Journal of Econometrics, 87 (August 1998), 115-43. 
Bom, Pedro R., and Jenny E. Ligthart, "What Have we Learned from Three Decades of Research on the Productivity of Public Capital?," Journal of Economic Surveys, 28 (December 2014), 889-916.

Bose, Niloy, Jill A. Holman, and Kyriakos C. Neanidis, "The Optimal Public Expenditure Financing Policy: Does The Level of Economic Development Matter?," Economic Inquiry, 3 (July 2007), 433-52.

Bottazzi, Laura, and Giovanni Peri, "The International Dynamics of R\&D and Innovation in the Short and in the Long Run," Working Paper No. 11524, National Bureau of Economic Research (July 2005).

Bougheas, Spiros, Panicos O. Demetriades, and Theofanis P.Mamouneas, "Infrastructure, Specialization, and Economic Growth," Canadian Journal of Economics, 33 (May 2000), 506-22.

Calderón, César, "Infrastructure and Growth in Africa," Policy Research Working Paper No. 4914, World Bank (April 2009).

Calderón, César, and Luis Servén, "The Effects of Infrastructure Development on Growth and Income Distribution," Policy Research Working Paper No. 3400, World Bank (September 2004).

_ , "Infrastructure in Latin America: An Update, 1980-2006," unpublished, World Bank (May 2009).

Chen, Hung-ju, "Educational Systems, Growth and Income Distribution: A Quantitative Analysis," Journal of Development Economics, 76 (April 2005), 325-53.

Chen, Xi, and Michael Funke, "The Dynamics of Catch-up and Skill and Technology Upgrading in China," Journal of Macroeconomics, 38 (December 2013), 465-80.

Czernich, Nina, Oliver Falck, Tobias Kretschmer, and Ludger Woessmann, "Broadband Infrastructure and Economic Growth," Economic Journal, 121 (May 2011), 505-32.

Devarajan, Shantayanan, Vinaya Swaroop, and Heng-fu Zou, "The Composition of Public Expenditure and Economic Growth," Journal of Monetary Economics, 37 (April 1996), 313-44.

Dinopoulos, Elias, and Peter Thompson, "Endogenous Growth in a Cross-Section of Countries," Journal of International Economics, 51 (August 2000), 335-62.

Easterly, William, "The Lost Decades: Explaining Developing Countries' Stagnation in spite of Reform 1980-1998," Journal of Economic Growth, 6 (June 2001), 135-57.

Égert, Balazs, Tomasz Koźluk, and Douglas Sutherland, "Infrastructure and Growth: Empirical Evidence," Working Paper No. 2700, CESifo (July 2009).

Esfahani, Hadi S., and Maria T. Ramírez, "Institutions, Infrastructure, and Economic Growth," Journal of Development Economics, 70 (April 2003), 443-77.

Funke, Michael, and Holger Strulik, "On Endogenous Growth with Physical Capital, Human Capital, and Product Variety," European Economic Review, 44 (March 2000), 
491-515.

Gómez, Manuel A., "Stages of Economic Development in an Innovation-Education Growth Model," Studies in Nonlinear Dynamics and Econometrics, 15 (September 2011), Article 6 .

Gómez, Manuel A., and Tiago N. Sequeira, "Optimal R\&D Subsidies in a Model with Physical Capital, Human Capital and Varieties," Economic Modelling, 30 (January 2013) 217-24.

Griliches, Zvi, "Patent Statistics as Economic Indicators: A Survey," Journal of Economic Literature, 28 (December 1990), 1661-707.

Grossman, Gene M., and Elhanan Helpman, "Quality Ladders in the Theory of Growth," Review of Economic Studies, 58 (January 1991), 43-61.

Grossmann, Volker, "How to Promote R\&D-based Growth? Public Education Expenditure on Scientists and Engineers versus R\&D Subsidies," Journal of Macroeconomics, 29 (December 2007), 891-911.

Gupta, Sanjeev, Erwin R. Tiongson, and Marijn Verhoeven, "Does Higher Government Spending Buy Better Results in Education and Health Care?" Working Paper No. 21, International Monetary Fund (February 1999).

Gupta, Sanjeev, Marijn Verhoeven, and Erwin R. Tiongson, "The Effectiveness of Government Spending on Education and Health Care in Developing and Transition Economies," European Journal of Political Economy, 18 (November 2002), 717-37.

Hansen, Lars P., "Large Sample Properties of Generalized Methods of Moments Estimators," Econometrica, 50 (July 1982), 1029-54.

Hulten, Charles R., "Infrastructure Capital and Economic Growth: How Well You Use It May Be More Important than How Much You Have," Working Paper No. 5847, National Bureau of Economic Research (December 1996).

Iacopetta, Maurizio, "Phases of Economic Development and the Transitional Dynamics of an Innovation-Education Growth Model," European Economic Review, 54 (February 2010), 317-30.

Kamps, Christophe, "New Estimates of Government Net Capital Stocks for 22 OECD Countries, 1960-2001," IMF Staff Papers, 53 (January 2006), 120-50.

Kellenberg, Derek K., "US Affiliates, Infrastructure and Growth: A Simultaneous Investigation of Critical Mass," Journal of International Trade and Economic Development, 18 (September 2009), 311-45.

Kneller, Richard, Michael F. Bleaney, and Norman Gemmell, "Fiscal Policy and Growth: Evidence from OECD Countries," Journal of Public Economics, 74 (November 1999), 171-90.

Loayza, Norman, Pablo Fajnzylber, and César Calderón, "Economic Growth in Latin America and the Caribbean: Stylized Facts, Explanations and Forecasts," Working 
Paper No. 265, Central Bank of Chile (June 2004).

McDermott, John, "Development Dynamics: Economic Integration and the Demographic Transition," Journal of Economic Growth, 7 (December 2002), 371-409.

Pavitt, Keith, "R\&D, Patenting and Innovative Activities: A Statistical Exploration," Research Policy (February 1982), 11, 33-51.

Prodan, Igor, "Influence of Research and Development Expenditures on Number of Patent Applications: Selected Case Studies in OECD Countries and Central Europe, 1981-2001," Applied Econometrics and International Development, 5 (2005), 5-22.

Redding, Stephen, "Low-Skill, Low Quality Trap: Strategic Complementarities between Human Capital and R\&D," Economic Journal, 106 (January 1996), 458-70.

Rioja, Felix K., "Roads versus Schooling: Growth Effects of Government Choices," Topics in Macroeconomics, 5 (March 2005), 1-22.

Röller, Lars-Hendrik, and Leonard Waverman, "Telecommunications Infrastructure and Economic Development: A Simultaneous Approach," American Economic Review, 91 (September 2001), 909-23.

Romer, Paul M., "Endogenous Technological Change," Journal of Political Economy, 98 (October 1990), s71-s102.

Roodman, David, "A Note on the Theme of Too Many Instruments," Oxford Bulletin of Economics and Statistics, 71 (January 2009), 135-58.

Schiffbauer, Marc, "Calling for Innovations: Infrastructure and Sources of Growth," Working Paper No. 18, Economic and Social Research Institute (May 2007).

Sequeira, Tiago N., "R\&D Spillovers in an Endogenous Growth Model with Physical Capital, Human Capital, and Varieties," Macroeconomic Dynamics, 15 (April 2011), 223-39.

Shioji, Etsuro, "Public Capital and Economic Growth: A Convergence Approach," Journal of Economic Growth, 6 (September 2001), 205-27.

Sokoloff, Kenneth L., "Inventive Activity in early Industrial America: Evidence from Patent Records," Journal of Economic History, 48 (December 1988), 813-50.

Stock, James H., and Motohiro Yogo, "Testing for weak instruments in linear regression." In Donald W.K. Andrews and James H. Stock, eds, Identification and Inference for Econometric Models: Essays in Honor of Thomas Rothenberg, Cambridge University Press, Cambridge (2005), pp. 80-108.

Straub, Stephane, "Infrastructure and Growth in Developing Countries: Recent Advances and Research Challenges," Policy Research Working Paper No. 4460, World Bank (January 2008).

Strulik, Holger, "The Role of Human Capital and Population Growth in R\&D-based Models of Economic Growth," Review of International Economics, 13 (February 2005), 129-45. 
Trajtenberg, Manuel, Patents as Indicators of Innovation, Economic Analysis of Product Innovation, Harvard University Press (Cambridge: 1990).

Ulku, Hulya, "R\&D, Innovation and Output: Evidence from OECD and non-OECD Countries," Applied Economics, 39 (February 2007a), 291-307.

"R\&D, Innovation, and Growth: Evidence from Four Manufacturing Sectors in OECD Countries," Oxford Economic Papers, 59 (April 2007b), 513-35. 


\section{Appendix A \\ Dynamic System and Steady-State Growth}

Substituting for $s_{t}$ from (3) in (2) yields the lifetime budget constraint,

$$
c_{t}^{t}+\frac{c_{t+1}^{t}}{1+r_{t+1}}=(1-\tau) e_{t} w_{t}
$$

Each individual maximizes (1) with respect to $c_{t}^{t}$ and $c_{t+1}^{t}$, subject to the intertemporal budget constraint (A1) and $c_{t}^{t}, c_{t+1}^{t}>0$. The first-order conditions give the standard Euler equation

$$
\frac{c_{t+1}^{t}}{c_{t}^{t}}=\frac{1+r_{t+1}}{\eta_{C}(1+\rho)}
$$

Substituting this result in (A1) yields

$$
c_{t}^{t}=\left[\frac{\eta_{C}(1+\rho)}{1+\eta_{C}(1+\rho)}\right](1-\tau) e_{t} w_{t},
$$

so that

$$
s_{t}=\sigma(1-\tau) e_{t} w_{t}
$$

where $\sigma=1 /\left[1+\eta_{C}(1+\rho)\right]<1$ is the marginal propensity to save.

Substituting this result in $(25)$ yields

$$
K_{t+1}^{P}=\sigma(1-\tau) e_{t} w_{t} \bar{N}
$$

From (22) and (24),

$$
K_{t+1}^{I}=v_{I} \tau e_{t} w_{t} \bar{N}
$$

Combining (A5) and (A6), this expression yields

$$
k_{t+1}^{I}=\frac{K_{t+1}^{I}}{K_{t+1}^{P}}=\frac{v_{I} \tau}{\sigma(1-\tau)}=J,
$$

which is constant over time.

To study the dynamics, note first that (10), together with (A7), yields

$$
Y_{t}=J^{\varepsilon} m_{t}^{\gamma / \eta} z_{t}^{\beta} x_{t}^{\gamma} K_{t}^{P}
$$

where, as defined in the text, $m_{t}=M_{t} / K_{t}^{P}$ and $z_{t}=E_{t} / K_{t}^{P}$. 
From (11), (15) and (A7),

$$
x_{t}=\frac{\gamma \eta}{[1+\varphi(J)] \theta}\left(\frac{Y_{t}}{K_{t}^{P}} \frac{K_{t}^{P}}{M_{t}}\right)=\frac{\gamma \eta}{[1+\varphi(J)] \theta}\left(\frac{Y_{t}}{K_{t}^{P}}\right) m_{t}^{-1} .
$$

Substituting this result in (A8) and rearranging yields

$$
\left(\frac{Y_{t}}{K_{t}^{P}}\right)^{1-\gamma}=\left[\frac{J^{\varepsilon}(\gamma \eta)^{\gamma}}{[1+\varphi(J)]^{\gamma} \theta^{\gamma}}\right] z_{t}^{\beta} m_{t}^{(\gamma / \eta-\gamma)},
$$

that is,

$$
\frac{Y_{t}}{K_{t}^{P}}=\Lambda_{1} m_{t}^{\Psi_{1}} z_{t}^{\Omega_{1}}
$$

where

$$
\begin{gathered}
\Lambda_{1}=\left[\frac{J^{\varepsilon}(\gamma \eta)^{\gamma}}{[1+\varphi(J)]^{\gamma} \theta^{\gamma}}\right]^{1 /(1-\gamma)}, \\
\Psi_{1}=\frac{\gamma\left(\eta^{-1}-1\right)}{1-\gamma}, \quad \Omega_{1}=\frac{\beta}{1-\gamma} .
\end{gathered}
$$

From (16), (17), and (A7),

$$
p_{t}^{M}=\frac{(1-\eta) \gamma}{1+\varphi(J)}\left(\frac{Y_{t}}{M_{t}}\right),
$$

which can be rearranged to give

$$
p_{t}^{M}=\frac{(1-\eta) \gamma}{1+\varphi(J)}\left(\frac{Y_{t}}{K_{t}^{P}}\right) m_{t}^{-1} .
$$

From (22),

$$
G_{t}^{h}=v_{h} \tau e_{t} w_{t} \bar{N}, \quad h=E, R
$$

Substituting (A11) and (A12) for $h=R$ in (20), holding with equality, and using (A7), yields, with $w_{t}^{R}=w_{t}$,

$$
w_{t}=\left(v_{R} \tau w_{t} \bar{N}\right)^{\phi_{1}}\left(m_{t} z_{t}^{-1}\right)^{\phi_{2}} J^{\phi_{3}} \frac{(1-\eta) \gamma}{1+\varphi(J)}\left(\frac{Y_{t}}{K_{t}^{P}}\right) m_{t}^{-1} .
$$

Substituting (A10) in (A13) yields the equilibrium wage as a function of $m_{t}$ and $z_{t}$.

$$
w_{t}=\Lambda_{2} m_{t}^{\Psi_{2}} z_{t}^{\Omega_{2}}
$$


with

$$
\begin{gathered}
\Lambda_{2}=\left\{\left(v_{R} \tau\right)^{\phi_{1}} \bar{N}^{\phi_{1}} J^{\phi_{3}} \frac{(1-\eta) \gamma}{1+\varphi(J)} \Lambda_{1}\right\}^{1 /\left(1-\phi_{1}\right)}, \\
\Psi_{2}=\frac{\Psi_{1}+\phi_{2}-1}{1-\phi_{1}}, \quad \Omega_{2}=\frac{\Omega_{1}-\phi_{2}}{1-\phi_{1}} .
\end{gathered}
$$

Now, from (18), (A7), and (A12) for $h=E$,

$$
\frac{E_{t+1}}{E_{t}}=\left(\frac{G_{t}^{E}}{\bar{N} E_{t}}\right)^{\nu_{1}}\left(k_{t}^{I}\right)^{\nu_{2}}=\left(v_{E} \tau w_{t}\right)^{\nu_{1}} J^{\nu_{2}},
$$

or equivalently, using (A14) to eliminate $w_{t}$,

$$
\frac{E_{t+1}}{E_{t}}=\Lambda_{3} m_{t}^{\Psi_{3}} z_{t}^{\Omega_{3}}
$$

where

$$
\begin{gathered}
\Lambda_{3}=\left(v_{E} \tau \Lambda_{2}\right)^{\nu_{1}} J^{\nu_{2}}, \\
\Psi_{3}=\Psi_{2} \nu_{1}, \quad \Omega_{3}=\Omega_{2} \nu_{1} .
\end{gathered}
$$

Using (A5), (A14), and (A15), the dynamics of $z_{t}$ are determined by

$$
z_{t+1}=\Lambda_{4} m_{t}^{\Psi_{4}} z_{t}^{\Omega_{4}}
$$

where

$$
\begin{gathered}
\Lambda_{4}=\frac{\Lambda_{3}}{\Lambda_{2} \sigma(1-\tau) \bar{N}}, \\
\Psi_{4}=\Psi_{3}-\Psi_{2}, \quad \Omega_{4}=\Omega_{3}-\Omega_{2} .
\end{gathered}
$$

Next, we need to determine the dynamics of $m_{t}$. Dividing (19) by $M_{t}$ yields

$$
\frac{M_{t+1}}{M_{t}}=1+\left(\frac{G_{t}^{R}}{E_{t}}\right)^{\phi_{1}}\left(z_{t} m_{t}^{-1}\right)^{1-\phi_{2}}\left(k_{t}^{I}\right)^{\phi_{3}}\left(\frac{N_{t}^{R}}{\bar{N}}\right)
$$

or equivalently, using (A7) and (A12) for $h=R$,

$$
\frac{M_{t+1}}{M_{t}}=1+\left[\frac{\left(v_{R} \tau \bar{N}\right)^{\phi_{1}} J^{\phi_{3}}}{\bar{N}}\right]\left(\frac{z_{t}}{m_{t}}\right)^{1-\phi_{2}} w_{t}^{\phi_{1}} N_{t}^{R} .
$$

To eliminate $N_{t}^{R}$ from this expression, we can substitute (A14) for $w_{t}$ in equation (27) to give

$$
N_{t}^{R}=\bar{N}-\beta\left(\frac{Y_{t}}{K_{t}^{P}}\right) z_{t}^{-1}\left(\Lambda_{2} m_{t}^{\Psi_{2}} z_{t}^{\Omega_{2}}\right)^{-1}
$$


Substituting (A10), (A14), and (A18) in (A17) yields

$$
\frac{M_{t+1}}{M_{t}}=1+\Lambda_{5} m_{t}^{\Psi_{5}} z_{t}^{\Omega_{5}}\left[\bar{N}-\Lambda_{6} m_{t}^{\Psi_{6}} z_{t}^{\Omega_{6}}\right]
$$

where

$$
\begin{gathered}
\Lambda_{5}=\left(\Lambda_{2} v_{R} \tau\right)^{\phi_{1}} J^{\phi_{3}} \bar{N}^{\phi_{1}-1}, \\
\Psi_{5}=\phi_{2}-1+\Psi_{2} \phi_{1}, \quad \Omega_{5}=1-\phi_{2}+\Omega_{2} \phi_{1}, \\
\Lambda_{6}=\beta \frac{\Lambda_{1}}{\Lambda_{2}}, \quad \Psi_{6}=\Psi_{1}-\Psi_{2}, \\
\Omega_{6}=\Omega_{1}-\Omega_{2}-1 .
\end{gathered}
$$

Combining (A5) and (A19) yields, noting that $M_{t} / E_{t}=m_{t} z_{t}^{-1}$,

$$
m_{t+1}=\frac{1+\Lambda_{5} m_{t}^{\Psi_{5}} z_{t}^{\Omega_{5}}\left[\bar{N}-\Lambda_{6} m_{t}^{\Psi_{6}} z_{t}^{\Omega_{6}}\right]}{\sigma(1-\tau) w_{t} \bar{N}} m_{t} z_{t}^{-1}
$$

Substituting (A14) in this expression and rearranging yields

$$
m_{t+1}=\frac{1+\Lambda_{5} m_{t}^{\Psi_{5}} z_{t}^{\Omega_{5}}\left[\bar{N}-\Lambda_{6} m_{t}^{\Psi_{6}} z_{t}^{\Omega_{6}}\right]}{\Lambda_{7} m_{t}^{\Psi_{7}} z_{t}^{\Omega_{7}}}
$$

where

$$
\begin{gathered}
\Lambda_{7}=\Lambda_{2} \sigma(1-\tau) \bar{N}, \\
\Psi_{7}=\Psi_{2}-1, \quad \Omega_{7}=1+\Omega_{2} .
\end{gathered}
$$

In the steady state, $z_{t}$ and $m_{t}$ are constant; from (A16) and (A20), they are solutions of the system

$$
\begin{gathered}
\tilde{z}=\left(\Lambda_{4} \tilde{m}^{\Psi_{4}}\right)^{1 / \Pi}, \\
\tilde{m}=\left\{\frac{1+\Lambda_{5} \tilde{m}^{\Psi_{5}} \tilde{z}^{\Omega_{5}}\left[\bar{N}-\Lambda_{6} \tilde{m}^{\Psi_{6}} \tilde{z}^{\Omega_{6}}\right]}{\Lambda_{7} \tilde{z}^{\Omega_{7}}}\right\}^{1 / \Phi},
\end{gathered}
$$

where

$$
\Pi=1-\Omega_{4}, \quad \Phi=1+\Psi_{7} .
$$

By implication, $E_{t}, M_{t}$, and $K_{t}^{P}$ (and thus $K_{t}^{I}$ from (A7)) grow also at the same constant rate. From (A10), in the steady state output grows also at the same rate as $K_{t}^{P}$ and other aggregate variables.

From (A14), the steady-state wage rate is $\tilde{w}=\Lambda_{2} \tilde{m}^{\Psi_{2}} \tilde{z}^{\Omega_{2}}$. Thus, from (A2), (A3), and (A4), individual consumption (in both periods of life) and savings (in the 
first period) grow at the same rate as $E_{t}$ and all other aggregate variables. From (5) the rental rate of capital is constant in the steady state.

From (A15) and (A19), the steady-state growth rate of the economy is given by the equivalent forms ${ }^{35,36}$

$$
\begin{gathered}
\gamma=\Lambda_{3} \tilde{m}^{\Psi_{3}} \tilde{z}^{\Omega_{3}}-1, \\
\gamma=\Lambda_{5} \tilde{m}^{\Psi_{5}} \tilde{z}^{\Omega_{5}}\left[\bar{N}-\Lambda_{6} \tilde{m}^{\Psi_{6}} \tilde{z}^{\Omega_{6}}\right],
\end{gathered}
$$

Equation (A23) corresponds to (30) in the text, with $\Gamma(J)=\Lambda_{3}, \Psi=\Psi_{3}$, and $\Omega=\Omega_{3}$.

\footnotetext{
${ }^{35}$ From (A5) and (A6), two other equivalent expessions can be derived for the growth rate.

${ }^{36}$ Note that the solution displays the typical "scale effect" that is characteristic of Romer-type models of innovation and growth. This scale effect can be eliminated in various ways; see for instance Eicher and Turnovsky (2000), Dinopoulos and Thomson (2000), and Perez-Sebastian (2007).
} 


\title{
Appendix B
}

\section{Country Sample and Data Sources}

\section{Country Sample (38)}

\author{
Argentina, Australia, Austria, Belgium, Canada, China, Czech Rep., Denmark, \\ Finland, France, Germany, Greece, Hungary, Iceland, Ireland, Israel, Italy, Japan, \\ Korea, Luxembourg, Mexico, Netherlands, New Zealand, Norway, Poland, Portugal, \\ Romania, Russian Federation, Singapore, Slovak Rep., Slovenia, South Africa, Spain, \\ Sweden, Switzerland, Turkey, United Kingdom, USA.
}

Table B1

Variables description and sources

\begin{tabular}{|c|c|c|}
\hline Variable & Definition & Source \\
\hline \multicolumn{3}{|l|}{ Benchmark Set } \\
\hline Stock of infrastructure & Telephone lines. & World Bank, WDI \\
\hline Education & $\begin{array}{l}\text { Share of tertiary level students in the total number of all students, according to } \\
\text { the International Standard Classification of Education } 1976 \text { and } 1997 \text { (ISCED- } \\
\text { 76, ISCED-97). For years } 1981 \text { to } 1995 \text { tertiary education includes ISCED-76 } \\
\text { levels 5, } 6 \text { and 7. For years } 1998 \text { and after, tertiary education includes ISCED-97 } \\
\text { levels 4, } 5 \text { and } 6 \text {. The first level of each of the classifications covers programs } \\
\text { that generally do not lead to a university degree but usually require successful } \\
\text { completion of a program at the upper secondary level. The second level covers } \\
\text { programs that lead to an award of a first university degree, and the third level } \\
\text { covers programs that lead to an award of a second or further university degree. }\end{array}$ & UNESCO \\
\hline Innovation & $\begin{array}{l}\text { Total number of patent applications per million inhabitants filed to the European } \\
\text { patent office (EPO) by year of filing, according to the inventor's country of } \\
\text { residence. The reference date of the application is the priority date, which is the } \\
\text { date of the first international filing of a patent and therefore the closest to the } \\
\text { invention date. }\end{array}$ & $\begin{array}{l}\text { OECD, Main Science } \\
\text { and Technology } \\
\text { Indicators }\end{array}$ \\
\hline Growth & $\begin{array}{l}\text { Annual percentage growth rate of GDP per capita based on constant local } \\
\text { currency. }\end{array}$ & World Bank, WDI \\
\hline \multirow[t]{5}{*}{ Stock of patents } & $\begin{array}{l}\text { The stock of patents for country } i \text { is calculated using the perpetual inventory } \\
\text { procedure in line with Bottazzi and Peri (2005) and Coe et al. (2009): }\end{array}$ & Author's calculations \\
\hline & Stock $_{i t}=$ Innovation $_{i t-1}+(1-\delta)$ Stock $_{i t-1}$ & \\
\hline & $\begin{array}{l}\text { where the depreciation rate, } \delta \text {, is assumed to be } 0.1 \text { The initial value of the } \\
\text { patent stock at time } t_{0} \text { is calculated as }\end{array}$ & \\
\hline & Stock $_{i t_{0}}=$ Innovation $_{i t_{0}} /\left(\delta+g_{i}\right)$ & \\
\hline & $\begin{array}{l}\text { where } g_{i} \text { is the annual average logarithmic growth rate of patenting in country } i \\
\text { from the earliest date data on patents are available }\left(t_{0}\right) \text { to } 1995 \text {. For most of the } \\
\text { countries } t_{0}=1977 \text {. }\end{array}$ & \\
\hline Initial GDP per capita & GDP per capita in constant 2000 USD for the first year of each period average. & World Bank, WDI \\
\hline $\begin{array}{l}\text { Infrastructure } \\
\text { expenditure }\end{array}$ & $\begin{array}{l}\text { Sum of fuel and energy, transportation, and communication expenditure of } \\
\text { consolidated central government (\% of GDP). }\end{array}$ & $\begin{array}{l}\text { International Monetary } \\
\text { Fund, GFS }\end{array}$ \\
\hline $\begin{array}{l}\text { Expenditure net of } \\
\text { infrastructure exp. }\end{array}$ & $\begin{array}{l}\text { Total expenditure of consolidated central government net of infrastructure } \\
\text { expenditure (\% of GDP). }\end{array}$ & $\begin{array}{l}\text { International Monetary } \\
\text { Fund, GFS }\end{array}$ \\
\hline Education expenditure & Education expenditure of consolidated central government (\% of GDP). & $\begin{array}{l}\text { International Monetary } \\
\text { Fund, GFS }\end{array}$ \\
\hline $\begin{array}{l}\text { Expenditure net of } \\
\text { infrastructure and } \\
\text { education exp. }\end{array}$ & $\begin{array}{l}\text { Total expenditure of consolidated central government net of infrastructure and } \\
\text { education expenditure (\% of GDP). }\end{array}$ & $\begin{array}{l}\text { International Monetary } \\
\text { Fund, GFS }\end{array}$ \\
\hline R\&D expenditure & $\begin{array}{l}\text { Gross domestic expenditure on research and development financed by the } \\
\text { government (\% of GDP). }\end{array}$ & $\begin{array}{l}\text { OECD, Main Science } \\
\text { and Technology } \\
\text { Indicators }\end{array}$ \\
\hline Expenditure net of & Total expenditure of consolidated central government net of infrastructure and & International Monetary \\
\hline
\end{tabular}




\begin{tabular}{|c|c|c|}
\hline $\begin{array}{l}\text { infrastructure and R\&D } \\
\text { exp. }\end{array}$ & R\&D expenditure (\% of GDP). & $\begin{array}{l}\text { Fund, GFS and OECD, } \\
\text { Main Science and } \\
\text { Technology Indicators }\end{array}$ \\
\hline Budget balance & Overall budget balance of consolidated central government (\% of GDP). & $\begin{array}{l}\text { International Monetary } \\
\text { Fund, GFS }\end{array}$ \\
\hline Non-tax revenue & Non-tax revenue of consolidated central government (\% of GDP). & $\begin{array}{l}\text { International Monetary } \\
\text { Fund, GFS }\end{array}$ \\
\hline Urban & Urban population (\% of total). & World Bank, WDI \\
\hline Population density & People per sq. km. & World Bank, WDI \\
\hline Life expectancy & Life expectancy at birth, total (years). & World Bank, WDI \\
\hline Population & Population, total. & World Bank, WDI \\
\hline Investment & Gross fixed capital formation (\% of GDP). & World Bank, WDI \\
\hline Fertility rate & Fertility rate (births per woman), total. & World Bank, WDI \\
\hline Trade & Trade (\% of GDP). & World Bank, WDI \\
\hline Inflation & Inflation, consumer prices (annual \%). & World Bank, WDI \\
\hline \multicolumn{3}{|l|}{ Sensitivity Set } \\
\hline Innovation_USPTO & $\begin{array}{l}\text { Defined the same way as "Innovation" but with regard to patent applications per } \\
\text { million inhabitants filed to the United States patent and trademark office } \\
\text { (USPTO). }\end{array}$ & $\begin{array}{l}\text { OECD, Main Science } \\
\text { and Technology } \\
\text { Indicators }\end{array}$ \\
\hline Innovation_PCT & $\begin{array}{l}\text { Defined the same way as "Innovation" but with regard to patent applications per } \\
\text { million inhabitants filed to the Patent Co-operation Treaty (PCT). The treaty } \\
\text { makes it possible to seek patent protection for an invention simultaneously in } \\
\text { each of a large number of countries by filling an "international" patent } \\
\text { application. }\end{array}$ & $\begin{array}{l}\text { OECD, Main Science } \\
\text { and Technology } \\
\text { Indicators }\end{array}$ \\
\hline $\begin{array}{l}\text { Mobile and fixed-line } \\
\text { telephone subscription }\end{array}$ & Mobile and fixed-line telephone subscribers. & World Bank, WDI \\
\hline Electricity production & Electricity production (kWh). & World Bank, WDI \\
\hline $\begin{array}{l}\text { Infrastructure quantity } \\
\text { synthetic index }\end{array}$ & $\begin{array}{l}0.6982 * \log (\text { telephone lines } \mathrm{pc})+0.6289 * \log (\text { electricity production } \\
\text { pc })+0.3419 * \log (\text { road length in } \mathrm{km} . \text { per sq. km. })\end{array}$ & Author's calculations \\
\hline Phone faults & Number of faults per year. & $\begin{array}{l}\text { OECD, } \\
\text { Telecommunications } \\
\text { Database }\end{array}$ \\
\hline $\begin{array}{l}\% \text { of transmission and } \\
\text { distribution losses }\end{array}$ & Electric power transmission and distribution losses (\% of output). & World Bank, WDI \\
\hline $\begin{array}{l}\text { Infrastructure quality } \\
\text { synthetic index }\end{array}$ & $\begin{array}{l}0.4649 * \text { (\% phone faults in total telephone lines })+0.6391 *(\% \text { of transmission } \\
\text { and distribution losses })+0.6127 * \text { (\% of non-paved roads in total roads })\end{array}$ & Author's calculations \\
\hline Threshold_tellinespc & High: 40 or greater lines per 100 people. & Author's calculations \\
\hline Threshold_mobfixsubpc & High: 50 or greater lines per 100 people. & Author's calculations \\
\hline Threshold_elecprodpc & High: 7,500 or greater kWh per capita. & Author's calculations \\
\hline Expenditure & Total expenditure of consolidated central government (\% of GDP). & $\begin{array}{l}\text { International Monetary } \\
\text { Fund, GFS }\end{array}$ \\
\hline
\end{tabular}


Table 1

Calibrated Parameter Values: Benchmark Case

\begin{tabular}{cll}
\hline \hline Parameter & Value & \\
\hline \hline Individuals & & \\
$\sigma$ & 0.04 & Annual discount rate \\
$\eta_{C}$ & 0.12 & Individual savings rate \\
Final good & 2.75 & Preference parameter, consumption \\
$\varepsilon$ & & \\
$\alpha$ & 0.17 & Elasticity wrt to public-private capital ratio \\
$\beta$ & 0.15 & Elasticity wrt private capital \\
$\gamma$ & 0.65 & Elasticity wrt effective labor \\
$\theta$ & 0.2 & Elasticity wrt intermediate goods \\
$\eta$ & & \\
Human capital & 0.25 & Parameter determining price elasticity \\
$\nu_{1}$ & 0.3 & Elasticity wrt public spending on education \\
$\nu_{2}$ & 0.2 & Elasticity wrt to public-private capital ratio \\
$\phi_{1}$ & & \\
$\phi_{2}$ & 0.3 & Elasticity wrt government spending on R\&D \\
$\phi_{3}$ & 0.7 & Elasticity wrt existing stock of ideas \\
$\tau$ & 0.0 & Elasticity wrt public-private capital ratio \\
Government & & \\
$v_{I}$ & 0.232 & Tax rate on output of final good \\
$v_{E}$ & 0.061 & Share of spending on infrastructure \\
$v_{R}$ & 0.171 & Share of spending on education \\
$\varphi_{0}$ & 0.05 & Share of spending on R\&D \\
$\varphi_{1}$ & 0.0 & Shift parameter, transportation costs \\
Transportation Costs & & Elasticity wrt to public-private capital ratio \\
\hline \hline
\end{tabular}


Table 2

Increase in Share of Spending on Infrastructure Investment $\underline{1}$ /

\begin{tabular}{|c|c|c|c|c|c|}
\hline \multirow[b]{2}{*}{ Financed by a cut in $v_{u}$} & \multirow[b]{2}{*}{ Baseline } & \multicolumn{4}{|c|}{ Absolute Deviations from Baseline } \\
\hline & & Benchmark & $v_{2}=0.5$ & $\phi_{3}=0.15$ & $\varphi_{1}=0.4$ \\
\hline Public-private capital ratio & 0.154 & 0.0252 & 0.0252 & 0.0252 & 0.0252 \\
\hline Human capital-private capital ratio & 0.626 & 0.0638 & 0.1753 & 0.0621 & 0.0627 \\
\hline \multirow[t]{2}{*}{ Growth rate of final output } & 0.033 & 0.0039 & 0.0086 & 0.0083 & 0.0062 \\
\hline & & \multicolumn{4}{|c|}{ Absolute Deviations from Baseline } \\
\hline Financed by a cut in $v_{E}$ & Baseline & Benchmark & $v_{2}=0.5$ & $\phi_{3}=0.15$ & $\varphi_{1}=0.4$ \\
\hline Public-private capital ratio & 0.154 & 0.0252 & 0.0252 & 0.0252 & 0.0252 \\
\hline Human capital-private capital ratio & 0.626 & 0.0240 & 0.1291 & 0.0224 & 0.0230 \\
\hline \multirow[t]{2}{*}{ Growth rate of final output } & 0.033 & 0.0022 & 0.0067 & 0.0058 & 0.0040 \\
\hline & & \multicolumn{4}{|c|}{ Absolute Deviations from Baseline } \\
\hline Financed by a cut in $v_{R}$ & Baseline & Benchmark & $v_{2}=0.5$ & $\phi_{3}=0.15$ & $\varphi_{1}=0.4$ \\
\hline Public-private capital ratio & 0.154 & 0.0252 & 0.0252 & 0.0252 & 0.0252 \\
\hline Human capital-private capital ratio & 0.626 & 0.0704 & 0.1830 & 0.0666 & 0.0687 \\
\hline Growth rate of final output & 0.033 & 0.0010 & 0.0054 & 0.0046 & 0.0029 \\
\hline
\end{tabular}

$1 /$ Increase in $v_{1}$ from 0.061 to $0.071 . v_{2}$ is the elasticity of human capital with respect to the publicprivate capital ratio; $\phi_{3}$ is the elasticity of the flow of new ideas with respect to the public-private capital ratio; and $\varphi_{1}$ is the elasticity of transportation costs with respect to the public-private capital ratio. In the benchmark case $\phi_{3}$ and $\varphi_{1}$ are both set equal to 0.0 , whereas $v_{2}$ is set equal to 0.2 .

Source: Authors' calculations. 
Table 3

Summary statistics

\begin{tabular}{|c|c|c|c|c|}
\hline Variable & Mean & Std. Dev. & Min & Max \\
\hline $\begin{array}{l}\text { Stock of infrastructure (per } \\
\text { capita) }\end{array}$ & 0.372 & 0.179 & 0.002 & 0.730 \\
\hline Education & 15.03 & 7.21 & 0.498 & 35.86 \\
\hline Innovation & 59.60 & 75.98 & 0.003 & 410.25 \\
\hline Growth & 3.10 & 2.83 & -8.28 & 12 \\
\hline Stock of patents (log) & 6.94 & 2.47 & 1.09 & 12.39 \\
\hline Initial GDP per capita (log) & 9.33 & 0.969 & 5.26 & 10.84 \\
\hline Infrastructure expenditure & 1.69 & 1.06 & 0.062 & 6.48 \\
\hline $\begin{array}{l}\text { Expenditure net of } \\
\text { infrastructure exp. }\end{array}$ & 31.34 & 11.30 & 9.93 & 58.70 \\
\hline Education expenditure & 2.85 & 1.71 & 0.190 & 10.02 \\
\hline $\begin{array}{l}\text { Expenditure net of } \\
\text { infrastructure and education } \\
\text { exp. }\end{array}$ & 28.59 & 10.51 & 9.042 & 53.81 \\
\hline R\&D expenditure & 0.588 & 0.250 & 0.127 & 1.26 \\
\hline $\begin{array}{l}\text { Expenditure net of } \\
\text { infrastructure and R\&D exp. }\end{array}$ & 30.82 & 11.24 & 9.93 & 58.70 \\
\hline Budget balance & -1.44 & 5.29 & -16.36 & 39.82 \\
\hline Non-tax revenue & 8.81 & 6.82 & -19.76 & 35.11 \\
\hline Urban & 71.70 & 14.80 & 21.3 & 100 \\
\hline Population density & 256.64 & 832.61 & 1.98 & 6413.06 \\
\hline Life expectancy & 74.75 & 4.69 & 50.84 & 82.25 \\
\hline Population (log) & 16.61 & 1.64 & 12.36 & 20.99 \\
\hline Investment & 23.32 & 5.30 & 15.11 & 47.76 \\
\hline Fertility rate & 1.84 & 0.576 & 1.14 & 4.55 \\
\hline Trade & 75.12 & 52.54 & 14.30 & 447.89 \\
\hline Inflation & 20.12 & 98.65 & -0.477 & 1397.58 \\
\hline Quantity of infrastructure index & $1.20 \mathrm{e}-09$ & 1.36 & -6.92 & 1.68 \\
\hline Quality of electric power & 7.92 & 3.57 & 2.72 & 32.74 \\
\hline Quality of infrastructure index & 0.002 & 1.29 & -1.51 & 5.07 \\
\hline
\end{tabular}

Note: A detailed description of the variables and their sources appears in Table B1. 
Table 4

Benchmark findings

\begin{tabular}{|c|c|c|c|c|c|c|c|c|c|c|c|c|}
\hline & \multirow{2}{*}{\multicolumn{4}{|c|}{ (1) }} & \multirow{2}{*}{\multicolumn{4}{|c|}{ (2) }} & \multirow{2}{*}{\multicolumn{4}{|c|}{ (3) }} \\
\hline & & & & & & & & & & & & \\
\hline & \multicolumn{4}{|c|}{ FE } & \multicolumn{4}{|c|}{ GMM-DIFF } & \multicolumn{4}{|c|}{ 3SLS } \\
\hline & infrastructure & education & innovation & growth & infrastructure & education & innovation & growth & infrastructure & education & innovation & growth \\
\hline Initial GDP per capita (log) & $\begin{array}{c}0.671 \\
(0.000)\end{array}$ & $\begin{array}{c}3.37 \\
(0.293)\end{array}$ & $\begin{array}{c}0.304 \\
(0.362)\end{array}$ & $\begin{array}{l}-9.30 \\
(0.000)\end{array}$ & $\begin{array}{c}0.637 \\
(0.347)\end{array}$ & $\begin{array}{c}8.45 \\
(0.122)\end{array}$ & $\begin{array}{c}0.568 \\
(0.004)\end{array}$ & $\begin{array}{l}-12.16 \\
(0.000)\end{array}$ & $\begin{array}{c}0.955 \\
(0.000)\end{array}$ & $\begin{array}{l}10.06 \\
(0.002)\end{array}$ & $\begin{array}{l}-0.750 \\
(0.052)\end{array}$ & $\begin{array}{l}-6.77 \\
(0.000)\end{array}$ \\
\hline Infrastructure expenditure & $\begin{array}{c}-0.202 \\
(0.000)\end{array}$ & $\begin{array}{c}0.571 \\
(0.344)\end{array}$ & $\begin{array}{l}-0.004 \\
(0.942)\end{array}$ & & $\begin{array}{c}-0.072 \\
(0.439)\end{array}$ & $\begin{array}{c}0.361 \\
(0.565)\end{array}$ & $\begin{array}{c}-0.098 \\
(0.004)\end{array}$ & & $\begin{array}{l}-0.156 \\
(0.000)\end{array}$ & $\begin{array}{c}0.409 \\
(0.510)\end{array}$ & $\begin{array}{c}0.109 \\
(0.092)\end{array}$ & \\
\hline $\begin{array}{l}\text { Expenditure net of infrastructure } \\
\text { exp. }\end{array}$ & $\begin{array}{l}-0.009 \\
(0.113)\end{array}$ & & & & $\begin{array}{l}-0.001 \\
(0.944)\end{array}$ & & & & $\begin{array}{l}-0.013 \\
(0.003)\end{array}$ & & & \\
\hline Education expenditure & & $\begin{array}{c}0.181 \\
(0.618)\end{array}$ & & & & $\begin{array}{c}-\mathbf{- 0 . 0 9 8} \\
(0.843)\end{array}$ & & & & $\begin{array}{c}0.490 \\
(0.069)\end{array}$ & & \\
\hline $\begin{array}{l}\text { Expenditure net of infrastructure } \\
\text { and education exp. }\end{array}$ & & $\begin{array}{c}0.156 \\
(0.074)\end{array}$ & & & & $\begin{array}{l}-0.165 \\
(0.068)\end{array}$ & & & & $\begin{array}{c}0.468 \\
(0.000)\end{array}$ & & \\
\hline $\mathrm{R} \& \mathrm{D}$ expenditure & & & $\begin{array}{c}0.585 \\
(0.004)\end{array}$ & & & & $\begin{array}{c}0.370 \\
(0.027)\end{array}$ & & & & $\begin{array}{c}0.629 \\
(0.001)\end{array}$ & \\
\hline $\begin{array}{l}\text { Expenditure net of infrastructure } \\
\text { and R\&D exp. }\end{array}$ & & & $\begin{array}{c}0.007 \\
(0.378)\end{array}$ & & & & $\begin{array}{c}0.017 \\
(0.002)\end{array}$ & & & & $\begin{array}{c}0.008 \\
(0.394)\end{array}$ & \\
\hline Budget balance & $\begin{array}{l}-0.013 \\
(0.067)\end{array}$ & $\begin{array}{c}0.060 \\
(0.591)\end{array}$ & $\begin{array}{c}0.008 \\
(0.345)\end{array}$ & & $\begin{array}{l}-0.005 \\
(0.585)\end{array}$ & $\begin{array}{l}0.007 \\
(0.959)\end{array}$ & $\begin{array}{c}0.028 \\
(0.000)\end{array}$ & & $\begin{array}{l}-0.023 \\
(0.040)\end{array}$ & $\begin{array}{c}0.269 \\
(0.009)\end{array}$ & $\begin{array}{c}0.021 \\
(0.040)\end{array}$ & \\
\hline Non-tax revenue & $\begin{array}{c}0.005 \\
(0.187)\end{array}$ & $\begin{array}{c}0.065 \\
(0.353)\end{array}$ & $\begin{array}{l}-0.017 \\
(0.002)\end{array}$ & & $\begin{array}{c}0.003 \\
(0.775)\end{array}$ & $\begin{array}{c}-0.083 \\
(0.167)\end{array}$ & $\begin{array}{c}-0.020 \\
(0.000)\end{array}$ & & $\begin{array}{c}0.008 \\
(0.022)\end{array}$ & $\begin{array}{c}0.036 \\
(0.561)\end{array}$ & $\begin{array}{l}-0.025 \\
(0.000)\end{array}$ & \\
\hline Urban & $\begin{array}{c}0.056 \\
(0.000)\end{array}$ & $\begin{array}{l}-0.427 \\
(0.014)\end{array}$ & & & $\begin{array}{c}0.139 \\
(0.001)\end{array}$ & $\begin{array}{c}-0.488 \\
(0.420)\end{array}$ & & & $\begin{array}{c}0.017 \\
(0.068)\end{array}$ & $\begin{array}{c}-0.173 \\
(0.247)\end{array}$ & & \\
\hline Population density & $\begin{array}{c}0.001 \\
(0.523)\end{array}$ & & & & $\begin{array}{c}0.001 \\
(0.893)\end{array}$ & & & & $\begin{array}{c}0.001 \\
(0.421)\end{array}$ & & & \\
\hline Life expectancy & & $\begin{array}{c}1.54 \\
(0.001)\end{array}$ & & & & $\begin{array}{c}0.204 \\
(0.801)\end{array}$ & & & & $\begin{array}{c}1.11 \\
(0.005)\end{array}$ & & \\
\hline Population (log) & & $\begin{array}{l}-25.72 \\
(0.000)\end{array}$ & & & & $\begin{array}{c}-48.47 \\
\mathbf{( 0 . 0 0 1 )}\end{array}$ & & & & $\begin{array}{l}-35.16 \\
(0.000)\end{array}$ & & \\
\hline Stock of infrastructure (log) & & $\begin{array}{c}8.86 \\
(0.000)\end{array}$ & $\begin{array}{c}0.337 \\
(0.044)\end{array}$ & $\begin{array}{c}0.945 \\
(0.051)\end{array}$ & & $\begin{array}{c}10.45 \\
(0.000)\end{array}$ & $\begin{array}{c}0.186 \\
(0.015)\end{array}$ & $\begin{array}{c}2.69 \\
(0.001)\end{array}$ & & $\begin{array}{c}16.87 \\
(0.000)\end{array}$ & $\begin{array}{c}0.614 \\
(0.020)\end{array}$ & $\begin{array}{c}1.74 \\
(\mathbf{0 . 0 0 0})\end{array}$ \\
\hline Stock of patents (log) & & $\begin{array}{c}0.428 \\
(0.569)\end{array}$ & $\begin{array}{c}0.692 \\
(0.000)\end{array}$ & & & $\begin{array}{c}4.36 \\
(0.021)\end{array}$ & $\begin{array}{c}0.476 \\
(0.000)\end{array}$ & & & $\begin{array}{l}-1.62 \\
(0.041)\end{array}$ & $\begin{array}{l}0.428 \\
(0.000)\end{array}$ & \\
\hline Education & & & $\begin{array}{c}0.015 \\
(0.039)\end{array}$ & $\begin{array}{c}0.104 \\
(0.002)\end{array}$ & & & $\begin{array}{c}0.038 \\
(0.000)\end{array}$ & $\begin{array}{l}-0.008 \\
(0.802)\end{array}$ & & & $\begin{array}{c}0.075 \\
(0.000)\end{array}$ & $\begin{array}{c}-0.110 \\
(0.024)\end{array}$ \\
\hline Innovation (log) & & & & $\begin{array}{c}0.992 \\
(0.001)\end{array}$ & & & & $\begin{array}{c}1.30 \\
(0.000)\end{array}$ & & & & $\begin{array}{c}1.14 \\
(0.019)\end{array}$ \\
\hline Investment & & & & $\begin{array}{c}0.134 \\
(0.003)\end{array}$ & & & & $\begin{array}{c}0.243 \\
(0.000)\end{array}$ & & & & $\begin{array}{c}0.182 \\
(0.000)\end{array}$ \\
\hline Fertility rate & & & & $\begin{array}{c}-0.042 \\
(0.953)\end{array}$ & & & & $\begin{array}{c}1.01 \\
(0.205)\end{array}$ & & & & $\begin{array}{c}-1.11 \\
(0.046)\end{array}$ \\
\hline Trade & & & & $\begin{array}{c}0.062 \\
(0.000)\end{array}$ & & & & $\begin{array}{c}0.082 \\
(0.000)\end{array}$ & & & & $\begin{array}{c}0.085 \\
(0.000)\end{array}$ \\
\hline Inflation & & & & $\begin{array}{l}-0.001 \\
(0.421)\end{array}$ & & & & $\begin{array}{l}-0.002 \\
(0.000)\end{array}$ & & & & $\begin{array}{l}-0.038 \\
(0.010)\end{array}$ \\
\hline Countries / Observations & $35 / 158$ & 34 / 142 & $33 / 124$ & $38 / 234$ & $35 / 121$ & $32 / 105$ & $32 / 89$ & $37 / 195$ & $33 / 123$ & $33 / 123$ & $33 / 123$ & $33 / 123$ \\
\hline & 0.754 & 0.772 & 0.924 & 0.394 & & & & & 0.993 & 0.909 & 0.985 & 0.638 \\
\hline Number of Instruments & & & & & 24 & 22 & 32 & 32 & & & & \\
\hline F-statistic & & & & & 53.51 & 1548.6 & 839574 & 6450.1 & 18693.2 & 10132.4 & 43259.7 & 240.4 \\
\hline Hansen J-statistic ( $p$-value) & & & & & 0.142 & 0.375 & 0.488 & 0.339 & & & & \\
\hline $\operatorname{AR}(2)$ test ( $p$-value $)$ & & & & & 0.420 & 0.003 & 0.300 & 0.405 & & & & \\
\hline
\end{tabular}

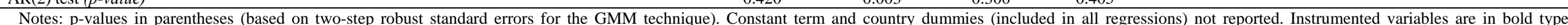

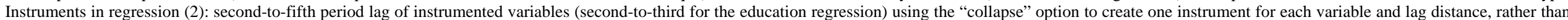
one for each time period, variable, and lag distance. 
Table 5

Elasticities of human capital accumulation, $R \& D$ production, and steady-state output level

\begin{tabular}{|c|c|c|c|}
\hline & FE & GMM-DIFF & 3SLS \\
\hline \multicolumn{4}{|l|}{$\begin{array}{l}\text { Human capital } \\
\text { accumulation }\end{array}$} \\
\hline Education expenditure $\left(v_{l}\right)$ & - & - & 0.093 \\
\hline Stock of infrastructure $\left(v_{2}\right)$ & 0.589 & 0.695 & 1.122 \\
\hline \multicolumn{4}{|l|}{ R\&D production } \\
\hline R\&D expenditure $\left(\varphi_{l}\right)$ & 0.344 & 0.217 & 0.369 \\
\hline Stock of patents $\left(\varphi_{2}\right)$ & 0.692 & 0.476 & 0.428 \\
\hline Stock of infrastructure $\left(\varphi_{3}\right)$ & 0.337 & 0.186 & 0.614 \\
\hline \multicolumn{4}{|l|}{ Growth of GDP pc } \\
\hline Stock of infrastructure & 0.101 & 0.221 & 0.257 \\
\hline \multicolumn{4}{|c|}{$\begin{array}{l}\text { Notes: Elasticity values based on coefficient estimates of Table } 2 \text {. The elasticity of human capital } \\
\text { accumulation with respect to education spending }\left(v_{l}\right) \text { is calculated by multiplying the coefficient } \\
\text { estimate of education expenditure in the education regression by the ratio of the mean value of education } \\
\text { expenditure to the mean value of education. The elasticity of human capital accumulation with respect to } \\
\text { the stock of infrastructure }\left(v_{2}\right) \text { is calculated by dividing the coefficient estimate of infrastructure stock in } \\
\text { the education regression by the mean value of education. The elasticity of R\&D production with respect } \\
\text { to government spending on R\&D }\left(\varphi_{I}\right) \text { is calculated by multiplying the coefficient estimate of R\&D } \\
\text { expenditure in the innovation regression by the mean value of R\&D expenditure. The elasticity of the } \\
\text { steady-state output level with respect to the stock of infrastructure is calculated by dividing the } \\
\text { coefficient estimate of infrastructure stock in the growth regression by the coefficient estimate of GDP } \\
\text { per capita in the same regression. Mean values of variables can be found in Table } 1 \text {. A dash corresponds } \\
\text { to a coefficient estimate with no statistical significance. }\end{array}$} \\
\hline
\end{tabular}


Table 6

Testing the proxy of innovation: alternative definitions

\begin{tabular}{|c|c|c|c|c|c|c|c|c|c|c|c|c|}
\hline & \multicolumn{4}{|c|}{$\begin{array}{c}\text { (1) } \\
\text { European Patent Office (EPO) }\end{array}$} & \multicolumn{4}{|c|}{$\begin{array}{c}\text { (2) } \\
\text { US Patent and Trademark Office (USPTO) }\end{array}$} & \multicolumn{4}{|c|}{$\begin{array}{c}\text { (3) } \\
\text { Patent Co-operation Treaty (PCT) }\end{array}$} \\
\hline & infrastructure & education & innovation & growth & infrastructure & education & innovation & growth & infrastructure & education & innovation & growth \\
\hline Initial GDP per capita (log) & $\begin{array}{c}0.955 \\
(0.000)\end{array}$ & $\begin{array}{c}10.06 \\
(0.002)\end{array}$ & $\begin{array}{l}-0.750 \\
(0.052)\end{array}$ & $\begin{array}{l}-6.77 \\
(0.000)\end{array}$ & $\begin{array}{c}0.929 \\
(0.000)\end{array}$ & $\begin{array}{c}3.48 \\
(0.264)\end{array}$ & $\begin{array}{c}-0.761 \\
(0.141)\end{array}$ & $\begin{array}{l}-5.64 \\
(0.000)\end{array}$ & $\begin{array}{c}0.955 \\
(0.000)\end{array}$ & $\begin{array}{c}7.25 \\
(0.029)\end{array}$ & $\begin{array}{c}0.490 \\
(0.408)\end{array}$ & $\begin{array}{l}-5.77 \\
(0.001)\end{array}$ \\
\hline Infrastructure expenditure & $\begin{array}{l}-0.156 \\
(0.000)\end{array}$ & $\begin{array}{c}0.409 \\
(0.510)\end{array}$ & $\begin{array}{c}0.109 \\
(0.092)\end{array}$ & & $\begin{array}{l}-0.156 \\
(0.000)\end{array}$ & $\begin{array}{c}0.113 \\
(0.858)\end{array}$ & $\begin{array}{c}-0.224 \\
(0.027)\end{array}$ & & $\begin{array}{l}-0.156 \\
(0.000)\end{array}$ & $\begin{array}{c}0.417 \\
(0.509)\end{array}$ & $\begin{array}{l}-0.028 \\
(0.786)\end{array}$ & \\
\hline $\begin{array}{l}\text { Expenditure net of infrastructure } \\
\text { exp. }\end{array}$ & $\begin{array}{l}-0.013 \\
(0.003)\end{array}$ & & & & $\begin{array}{l}-0.013 \\
(0.003)\end{array}$ & & & & $\begin{array}{l}-0.013 \\
(0.004)\end{array}$ & & & \\
\hline Education expenditure & & $\begin{array}{c}0.490 \\
(0.069)\end{array}$ & & & & $\begin{array}{c}1.46 \\
(0.000)\end{array}$ & & & & $\begin{array}{c}0.847 \\
(0.003)\end{array}$ & & \\
\hline $\begin{array}{l}\text { Expenditure net of infrastructure } \\
\text { and education exp. }\end{array}$ & & $\begin{array}{c}0.468 \\
(0.000)\end{array}$ & & & & $\begin{array}{c}0.131 \\
(0.153)\end{array}$ & & & & $\begin{array}{c}0.317 \\
(0.000)\end{array}$ & & \\
\hline $\mathrm{R} \& \mathrm{D}$ expenditure & & & $\begin{array}{c}0.629 \\
(0.001)\end{array}$ & & & & $\begin{array}{c}0.091 \\
(0.727)\end{array}$ & & & & $\begin{array}{c}0.535 \\
(0.085)\end{array}$ & \\
\hline $\begin{array}{l}\text { Expenditure net of infrastructure } \\
\text { and R\&D exp. }\end{array}$ & & & $\begin{array}{c}0.008 \\
(0.394)\end{array}$ & & & & $\begin{array}{c}0.013 \\
(0.366)\end{array}$ & & & & $\begin{array}{c}0.030 \\
(0.051)\end{array}$ & \\
\hline Budget balance & $\begin{array}{c}-0.023 \\
(0.040)\end{array}$ & $\begin{array}{c}0.269 \\
(0.009)\end{array}$ & $\begin{array}{c}0.021 \\
(0.040)\end{array}$ & & $\begin{array}{l}-0.011 \\
(0.047)\end{array}$ & $\begin{array}{c}0.065 \\
(0.566)\end{array}$ & $\begin{array}{c}0.004 \\
(0.818)\end{array}$ & & $\begin{array}{c}-0.012 \\
(0.041)\end{array}$ & $\begin{array}{c}0.178 \\
(0.077)\end{array}$ & $\begin{array}{c}0.025 \\
(0.134)\end{array}$ & \\
\hline Non-tax revenue & $\begin{array}{c}0.008 \\
(0.022)\end{array}$ & $\begin{array}{c}0.036 \\
(0.561)\end{array}$ & $\begin{array}{c}-0.025 \\
(0.000)\end{array}$ & & $\begin{array}{c}0.008 \\
(0.024)\end{array}$ & $\begin{array}{c}0.106 \\
(0.088)\end{array}$ & $\begin{array}{c}0.021 \\
(0.028)\end{array}$ & & $\begin{array}{c}0.008 \\
(0.030)\end{array}$ & $\begin{array}{c}0.053 \\
(0.395)\end{array}$ & $\begin{array}{c}0.008 \\
(0.389)\end{array}$ & \\
\hline Urban & $\begin{array}{c}0.017 \\
(0.068)\end{array}$ & $\begin{array}{c}-0.173 \\
(0.247)\end{array}$ & & & $\begin{array}{c}0.018 \\
(0.062)\end{array}$ & $\begin{array}{c}-0.038 \\
(0.776)\end{array}$ & & & $\begin{array}{c}0.019 \\
(0.056)\end{array}$ & $\begin{array}{c}-0.155 \\
(0.317)\end{array}$ & & \\
\hline Population density & $\begin{array}{c}0.001 \\
(0.421)\end{array}$ & & & & $\begin{array}{c}0.002 \\
(0.297)\end{array}$ & & & & $\begin{array}{c}0.001 \\
(0.576)\end{array}$ & & & \\
\hline Life expectancy & & $\begin{array}{c}1.11 \\
(0.005)\end{array}$ & & & & $\begin{array}{c}1.41 \\
(0.000)\end{array}$ & & & & $\begin{array}{c}1.08 \\
(0.005)\end{array}$ & & \\
\hline Population (log) & & $\begin{array}{l}-35.16 \\
(0.000)\end{array}$ & & & & $\begin{array}{l}-32.36 \\
(0.000)\end{array}$ & & & & $\begin{array}{l}-32.05 \\
(0.000)\end{array}$ & & \\
\hline Stock of infrastructure (log) & & $\begin{array}{c}16.87 \\
(0.000)\end{array}$ & $\begin{array}{c}0.614 \\
(0.020)\end{array}$ & $\begin{array}{c}1.74 \\
(0.000)\end{array}$ & & $\begin{array}{c}9.49 \\
(0.000)\end{array}$ & $\begin{array}{c}1.09 \\
(0.003)\end{array}$ & $\begin{array}{c}1.51 \\
(0.001)\end{array}$ & & $\begin{array}{c}14.13 \\
(0.000)\end{array}$ & $\begin{array}{c}2.18 \\
(0.000)\end{array}$ & $\begin{array}{c}1.30 \\
(0.015)\end{array}$ \\
\hline Stock of patents (log) & & $\begin{array}{l}-1.62 \\
(0.041)\end{array}$ & $\begin{array}{c}0.428 \\
(0.000)\end{array}$ & & & $\begin{array}{c}1.60 \\
(0.170)\end{array}$ & $\begin{array}{c}0.772 \\
(0.000)\end{array}$ & & & $\begin{array}{l}-0.223 \\
(0.660)\end{array}$ & $\begin{array}{l}0.618 \\
(0.000)\end{array}$ & \\
\hline Education & & & $\begin{array}{c}0.075 \\
(0.000)\end{array}$ & $\begin{array}{c}-0.110 \\
(0.024)\end{array}$ & & & $\begin{array}{l}-0.113 \\
(0.000)\end{array}$ & $\begin{array}{c}-0.016 \\
(0.777)\end{array}$ & & & $\begin{array}{l}-0.049 \\
(0.034)\end{array}$ & $\begin{array}{l}-0.122 \\
(0.027)\end{array}$ \\
\hline Innovation (log) & & & & $\begin{array}{c}1.14 \\
(0.019)\end{array}$ & & & & $\begin{array}{c}0.700 \\
(0.058)\end{array}$ & & & & $\begin{array}{c}0.551 \\
(0.051)\end{array}$ \\
\hline Investment & & & & $\begin{array}{c}0.182 \\
(0.000)\end{array}$ & & & & $\begin{array}{c}0.164 \\
(0.001)\end{array}$ & & & & $\begin{array}{c}0.176 \\
(0.001)\end{array}$ \\
\hline Fertility rate & & & & $\begin{array}{c}-1.11 \\
(0.046)\end{array}$ & & & & $\begin{array}{c}-0.849 \\
(0.311)\end{array}$ & & & & $\begin{array}{c}-1.13 \\
(0.206)\end{array}$ \\
\hline Trade & & & & $\begin{array}{c}0.085 \\
(0.000)\end{array}$ & & & & $\begin{array}{c}0.091 \\
(0.000)\end{array}$ & & & & $\begin{array}{c}0.086 \\
(0.000)\end{array}$ \\
\hline Inflation & & & & $\begin{array}{l}-0.038 \\
(0.010)\end{array}$ & & & & $\begin{array}{l}-0.041 \\
(0.005)\end{array}$ & & & & $\begin{array}{l}-0.047 \\
(0.001)\end{array}$ \\
\hline Countries / Observations & $33 / 123$ & $33 / 123$ & $33 / 123$ & $33 / 123$ & $33 / 123$ & $33 / 123$ & $33 / 123$ & $33 / 123$ & $33 / 123$ & $33 / 123$ & $33 / 123$ & $33 / 123$ \\
\hline & 0.993 & 0.909 & 0.985 & 0.638 & 0.993 & 0.908 & 0.970 & 0.653 & 0.993 & 0.912 & 0.977 & 0.616 \\
\hline F-statistic & 18693.2 & 10132.4 & 43259.7 & 240.4 & 21300 & 10223 & 18414 & $251 . .05$ & 21300 & 1291.08 & 13807 & 225.24 \\
\hline
\end{tabular}

otes. p-values in parentheses. Constant term and country dummies (included in all regressions) not reporte
of the endogenous variables are qualitatively the same when we use the rest of the estimation techniques. 
Table 7

Elasticities of human capital accumulation, $R \& D$ production, and steady-state output level

\begin{tabular}{|c|c|c|c|}
\hline & EPO & USPTO & PCT \\
\hline \multicolumn{4}{|l|}{$\begin{array}{l}\text { Human capital } \\
\text { accumulation }\end{array}$} \\
\hline Education expenditure $\left(v_{l}\right)$ & 0.093 & 0.275 & 0.160 \\
\hline Stock of infrastructure $\left(v_{2}\right)$ & 1.122 & 0.631 & 0.940 \\
\hline \multicolumn{4}{|l|}{ R\&D production } \\
\hline R\&D expenditure $\left(\varphi_{l}\right)$ & 0.369 & - & 0.314 \\
\hline Stock of patents $\left(\varphi_{2}\right)$ & 0.428 & 0.772 & 0.618 \\
\hline Stock of infrastructure $\left(\varphi_{3}\right)$ & 0.614 & 1.09 & 2.18 \\
\hline \multicolumn{4}{|l|}{ Growth of GDP pc } \\
\hline Stock of infrastructure & 0.257 & 0.267 & 0.225 \\
\hline
\end{tabular}

Notes: Elasticity values based on coefficient estimates of Table 4. For details see notes at bottom of Table 3. 
Table 8

Testing the proxy of infrastructure: alternative measures

Mobile and fixed-line telephone subscription

(2)

Electricity production

\begin{tabular}{|c|c|c|c|c|c|c|c|c|c|c|c|c|}
\hline & infrastructure & education & innovation & growth & infrastructure & education & innovation & growth & infrastructure & education & innovation & growth \\
\hline Initial GDP per capita (log) & $\begin{array}{c}2.70 \\
(0.000)\end{array}$ & $\begin{array}{c}0.781 \\
(0.830)\end{array}$ & $\begin{array}{c}0.257 \\
(0.317)\end{array}$ & $\begin{array}{l}-8.00 \\
(0.000)\end{array}$ & $\begin{array}{c}0.863 \\
(0.000)\end{array}$ & $\begin{array}{c}12.92 \\
(0.000)\end{array}$ & $\begin{array}{l}-1.089 \\
(0.006)\end{array}$ & $\begin{array}{l}-4.96 \\
(0.005)\end{array}$ & $\begin{array}{c}1.49 \\
(0.000)\end{array}$ & $\begin{array}{c}9.00 \\
(0.004)\end{array}$ & $\begin{array}{l}-0.336 \\
(0.377)\end{array}$ & $\begin{array}{l}-13.03 \\
(0.000)\end{array}$ \\
\hline Infrastructure expenditure & $\begin{array}{l}-0.112 \\
(0.096)\end{array}$ & $\begin{array}{l}-1.46 \\
(0.017)\end{array}$ & $\begin{array}{l}-0.022 \\
(0.639)\end{array}$ & & $\begin{array}{l}-0.088 \\
(0.001)\end{array}$ & $\begin{array}{l}-0.969 \\
(0.147)\end{array}$ & $\begin{array}{c}0.074 \\
(0.247)\end{array}$ & & $\begin{array}{l}-0.173 \\
(0.000)\end{array}$ & $\begin{array}{c}0.112 \\
(0.852)\end{array}$ & $\begin{array}{c}0.121 \\
(0.052)\end{array}$ & \\
\hline $\begin{array}{l}\text { Expenditure net of infrastructure } \\
\text { exp. }\end{array}$ & $\begin{array}{l}-0.013 \\
(0.119)\end{array}$ & & & & $\begin{array}{c}0.008 \\
(0.006)\end{array}$ & & & & $\begin{array}{c}-0.015 \\
(0.009)\end{array}$ & & & \\
\hline Education expenditure & & $\begin{array}{c}0.595 \\
(0.035)\end{array}$ & & & & $\begin{array}{c}0.518 \\
(0.099)\end{array}$ & & & & $\begin{array}{c}0.873 \\
(0.002)\end{array}$ & & \\
\hline $\begin{array}{l}\text { Expenditure net of infrastructure } \\
\text { and education exp. }\end{array}$ & & $\begin{array}{c}0.389 \\
(0.000)\end{array}$ & & & & $\begin{array}{c}0.119 \\
(0.161)\end{array}$ & & & & $\begin{array}{c}0.476 \\
(0.000)\end{array}$ & & \\
\hline $\mathrm{R} \& \mathrm{D}$ expenditure & & & $\begin{array}{c}0.791 \\
(0.000)\end{array}$ & & & & $\begin{array}{c}0.440 \\
(0.025)\end{array}$ & & & & $\begin{array}{c}0.445 \\
(0.026)\end{array}$ & \\
\hline $\begin{array}{l}\text { Expenditure net of infrastructure } \\
\text { and R\&D exp. }\end{array}$ & & & $\begin{array}{c}0.016 \\
(0.020)\end{array}$ & & & & $\begin{array}{l}-0.005 \\
(0.476)\end{array}$ & & & & $\begin{array}{c}0.016 \\
(0.151)\end{array}$ & \\
\hline Budget balance & $\begin{array}{l}-0.017 \\
(0.118)\end{array}$ & $\begin{array}{c}0.182 \\
(0.064)\end{array}$ & $\begin{array}{c}0.018 \\
(0.017)\end{array}$ & & $\begin{array}{l}0.008 \\
(0.038)\end{array}$ & $\begin{array}{l}-0.026 \\
(0.808)\end{array}$ & $\begin{array}{c}0.011 \\
(0.280)\end{array}$ & & $\begin{array}{l}-0.011 \\
(0.139)\end{array}$ & $\begin{array}{c}0.258 \\
(0.009)\end{array}$ & $\begin{array}{c}0.022 \\
(0.041)\end{array}$ & \\
\hline Non-tax revenue & $\begin{array}{c}0.012 \\
(0.093)\end{array}$ & $\begin{array}{c}0.036 \\
(0.567)\end{array}$ & $\begin{array}{l}-0.017 \\
(0.000)\end{array}$ & & $\begin{array}{c}0.001 \\
(0.510)\end{array}$ & $\begin{array}{c}0.153 \\
(0.023)\end{array}$ & $\begin{array}{l}-0.022 \\
(0.001)\end{array}$ & & $\begin{array}{c}0.015 \\
(0.002)\end{array}$ & $\begin{array}{c}0.030 \\
(0.626)\end{array}$ & $\begin{array}{l}-0.024 \\
(0.000)\end{array}$ & \\
\hline Urban & $\begin{array}{c}0.001 \\
(0.949)\end{array}$ & $\begin{array}{c}0.106 \\
(0.506)\end{array}$ & & & $\begin{array}{c}0.002 \\
(0.681)\end{array}$ & $\begin{array}{c}0.029 \\
(0.861)\end{array}$ & & & $\begin{array}{l}-0.002 \\
(0.867)\end{array}$ & $\begin{array}{c}0.093 \\
(0.540)\end{array}$ & & \\
\hline Population density & $\begin{array}{c}0.005 \\
(0.196)\end{array}$ & & & & $\begin{array}{l}0.006 \\
(0.000)\end{array}$ & & & & $\begin{array}{c}0.004 \\
(0.146)\end{array}$ & & & \\
\hline Life expectancy & & $\begin{array}{l}-0.540 \\
(0.323)\end{array}$ & & & & $\begin{array}{c}1.34 \\
(0.002)\end{array}$ & & & & $\begin{array}{c}0.679 \\
(0.117)\end{array}$ & & \\
\hline Population (log) & & $\begin{array}{l}-28.44 \\
(0.000)\end{array}$ & & & & $\begin{array}{l}-32.90 \\
(0.001)\end{array}$ & & & & $\begin{array}{l}-20.25 \\
(0.002)\end{array}$ & & \\
\hline Stock of infrastructure (log) & & $\begin{array}{c}11.52 \\
(0.000)\end{array}$ & $\begin{array}{c}0.435 \\
(0.001)\end{array}$ & $\begin{array}{c}1.61 \\
(0.000)\end{array}$ & & $\begin{array}{l}13.00 \\
(0.021)\end{array}$ & $\begin{array}{c}0.635 \\
(0.095)\end{array}$ & $\begin{array}{c}2.08 \\
(0.000)\end{array}$ & & $\begin{array}{l}15.65 \\
(0.000)\end{array}$ & $\begin{array}{c}0.629 \\
(0.051)\end{array}$ & $\begin{array}{c}3.89 \\
(0.000)\end{array}$ \\
\hline Stock of patents (log) & & $\begin{array}{l}-0.555 \\
(0.479)\end{array}$ & $\begin{array}{c}0.391 \\
(0.000)\end{array}$ & & & $\begin{array}{l}-1.84 \\
(0.103)\end{array}$ & $\begin{array}{l}0.405 \\
(0.000)\end{array}$ & & & $\begin{array}{l}-3.25 \\
(0.000)\end{array}$ & $\begin{array}{c}0.340 \\
(0.001)\end{array}$ & \\
\hline Education & & & $\begin{array}{c}0.018 \\
(0.087)\end{array}$ & $\begin{array}{r}-0.185 \\
(0.002)\end{array}$ & & & $\begin{array}{c}0.093 \\
(0.000)\end{array}$ & $\begin{array}{c}-0.104 \\
(\mathbf{0 . 0 3 5 )}\end{array}$ & & & $\begin{array}{c}0.059 \\
(0.000)\end{array}$ & $\begin{array}{c}-0.056 \\
(0.210)\end{array}$ \\
\hline Innovation (log) & & & & $\begin{array}{c}1.50 \\
(0.003)\end{array}$ & & & & $\begin{array}{c}0.728 \\
(0.145)\end{array}$ & & & & $\begin{array}{c}1.13 \\
(0.053)\end{array}$ \\
\hline Investment & & & & $\begin{array}{c}0.197 \\
(0.000)\end{array}$ & & & & $\begin{array}{l}0.207 \\
(0.000)\end{array}$ & & & & $\begin{array}{c}0.155 \\
(0.002)\end{array}$ \\
\hline Fertility rate & & & & $\begin{array}{l}-1.16 \\
(0.043)\end{array}$ & & & & $\begin{array}{l}-1.32 \\
(0.019)\end{array}$ & & & & $\begin{array}{c}0.625 \\
(0.399)\end{array}$ \\
\hline Trade & & & & $\begin{array}{c}0.077 \\
(0.000)\end{array}$ & & & & $\begin{array}{c}0.079 \\
(0.000)\end{array}$ & & & & $\begin{array}{c}0.075 \\
(0.000)\end{array}$ \\
\hline Inflation & & & & $\begin{array}{c}-0.031 \\
(0.038) \\
\end{array}$ & & & & $\begin{array}{c}-0.042 \\
(0.006) \\
\end{array}$ & & & & $\begin{array}{c}-0.032 \\
(0.051) \\
\end{array}$ \\
\hline Countries / Observations & $33 / 123$ & $33 / 123$ & $33 / 123$ & $33 / 123$ & $33 / 123$ & $33 / 123$ & $33 / 123$ & $33 / 123$ & $33 / 120$ & $33 / 120$ & $33 / 120$ & $33 / 120$ \\
\hline & 0.978 & 0.897 & 0.994 & 0.608 & 0.996 & 0.896 & 0.983 & 0.652 & 0.972 & 0.921 & 0.988 & 0.626 \\
\hline F-statistic & 637440 & 9577 & 21177 & 230.93 & 115000 & 1062 & 11226 & 224.99 & 4913 & 1440 & 49511 & 243.46 \\
\hline
\end{tabular}

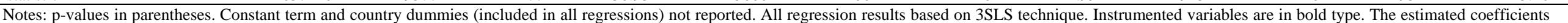
of the endogenous variables are qualitatively the same when we use the rest of the estimation techniques. 
Table 9

Elasticities of human capital accumulation, $R \& D$ production, and steady-state output level

\begin{tabular}{|c|c|c|c|}
\hline & $\begin{array}{l}\text { Mobile and fixed- } \\
\text { line subscriptions }\end{array}$ & $\begin{array}{l}\text { Electricity } \\
\text { production }\end{array}$ & $\begin{array}{c}\text { Infrastructure } \\
\text { quantity synthetic } \\
\text { index }\end{array}$ \\
\hline \multicolumn{4}{|l|}{$\begin{array}{l}\text { Human capital } \\
\text { accumulation }\end{array}$} \\
\hline Education expenditure $\left(v_{l}\right)$ & 0.112 & 0.098 & 0.165 \\
\hline Stock of infrastructure $\left(v_{2}\right)$ & 0.756 & 0.864 & 1.041 \\
\hline \multicolumn{4}{|l|}{ R\&D production } \\
\hline R\&D expenditure $\left(\varphi_{1}\right)$ & 0.465 & 0.258 & 0.756 \\
\hline Stock of patents $\left(\varphi_{2}\right)$ & 0.391 & 0.405 & 0.340 \\
\hline Stock of infrastructure $\left(\varphi_{3}\right)$ & 0.435 & 0.635 & 0.629 \\
\hline \multicolumn{4}{|l|}{ Growth of GDP pc } \\
\hline Stock of infrastructure & 0.201 & 0.419 & 0.298 \\
\hline
\end{tabular}


Table 10

Accounting for the quality of infrastructure

Mobile and fixed-line telephone subscription [phone faults]

infrastructure education innovation

2.75
$(0.000)$
-0.042
$(0.692)$
-0.040
$(0.001)$

Education expenditure

Expenditure net of infrastructure and education exp.

$\mathrm{R} \& \mathrm{D}$ expenditure

Expenditure net of infrastructure and $R \& D$ exp

Budget balance

Non-tax revenue

Urban

Population density

Life expectancy

Population (log)

Stock of infrastructure (log)

Quality of infrastructure

Stock of patents (log)

$-7.28$

$\begin{array}{ll}-7.28 & -0.189 \\ (0.191) & (0.598)\end{array}$

$-1.56$

$(0.102)$

$(0.598)$

-0.027
$(0.677)$

0.039

$(0.959)$

0.842

$(0.000)$

\section{(a)} growth
-17.19
$(0.000)$

Electricity production $\%$ of transmission and distribution losses

$\begin{array}{cccc}\text { infrastructure } & \text { education } & \text { innovation } & \text { growth } \\ 0.858 & 14.01 & -1.11 & -5.69 \\ (0.000) & (0.000 & (0.006) & (0.001)\end{array}$

$\begin{array}{ccc} & & 0.606 \\ & (0.004) \\ & -0.001 \\ & & (0.947) \\ -0.032 & 0.443 & 0.006\end{array}$

$\quad(0.000)$

$-0.088 \quad-0.992$

$(0.001) \quad(0.138)$

$(0.006)$
0.078

0.008

$(0.009)$

0.036

0.012

$(0.001)$

$-0.124$

(0.508)

$-0.017$

$(0.748)$

0.009

(0.326)

$(0.007)$

(0.138)

$(0.230)$

0.492

0.492
$(0.119)$

0.130

(0.126)

(n)

0.439

$(0.040)$

$\begin{array}{lll} & & -0.005 \\ & & (0.533) \\ 0.008 & -0.016 & 0.011\end{array}$

$\begin{array}{ccc}0.008 & -0.016 & 0.011 \\ (0.039) & (0.875) & (0.287) \\ 0.002 & 0.153 & -0.022\end{array}$

$\begin{array}{lll}0.002 & 0.153 & -0.022 \\ (0.424) & (0.024) & (0.000)\end{array}$

$(0.424) \quad(0.024)$

(0.424)

0.016

$(0.699)$

$(0.921)$

0.006

$-1.83$

$(0.073)$

-24.61
$(0.132)$

15.42
$(\mathbf{0 . 0 0 0})$

0.308

(0.071)

0.045

$(0.354)$

$\begin{array}{rr}-0.880 & 0.501\end{array}$

$(0.664) \quad(0.000)$

$0.046 \quad-0.232$

(0.001) (0.001)

4.52

(0.000)

0.390

Investment

Fertility rate

Trade

Inflation

Countries / Observations

$\mathrm{R}^{2}$

F-statistic

0.973
2784

$\begin{array}{llll}0.973 & 0.855 & 0.995 & 0.703 \\ 2784 & 628.64 & 59579 & 242.17\end{array}$

$(0.000)$
0.866

0.866
$(0.359)$

$(0.359)$
0.053

0.053

$-0.024$

1.36

$(0.002)$

$-31.19$

$(0.001)$
11.15

(0.044)

1.02

.018)

$\begin{array}{cc}\mathbf{( 0 . 0 6 9 )} & \mathbf{2 . 1 5} \\ 0.005 & (\mathbf{0 . 0 0 0 )}\end{array}$

$0.005 \quad-0.360$

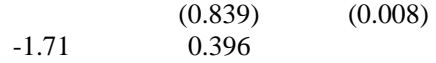

$\begin{array}{ll}-1.71 & 0.396 \\ (0.128) & (0.000)\end{array}$

$0.094 \quad-0.081$

$\begin{array}{ll}(0.000) & (0.095)\end{array}$

0.594

0.594
$(0.221)$

$(0.221)$
0.218

$(0.000)$

-1.21
$(0.029)$

$(0.029)$

0.083
$(0.000)$

$-0.034$

(0.024)

(0.135)

$27 / 76 \quad 33 / 123$

$\begin{array}{lcc}3 / 123 & 33 / 123 & 33 / 123 \\ 0.996 & 0.894 & 0.983 \\ 35798 & 1054 & 11104\end{array}$

$33 / 123$
0.674

\begin{tabular}{llll}
1054 & 11104 & 247.65 & 0.980 \\
\hline
\end{tabular}

$4032 \quad 6429$

(3)

Infrastructure quality synthetic index

of the endogenous variables are qualitatively the same when we use the rest of the estimation techniques.

\begin{tabular}{cccc} 
& education & innovation & growth \\
\hline 1.25 & 1.13 & 0.041 & -17.75 \\
$(0.000)$ & $(0.815)$ & $(0.923)$ & $(0.000)$
\end{tabular}

$\begin{array}{ccc}1.25 & (0.815) & (0.923) \\ -0.112 & 0.298 & 0.041\end{array}$

$(0.088) \quad(0.737) \quad(0.589)$

$-0.022$

$(0.004)$

2.12

$(0.003)$

0.720

(0.000)

$\begin{array}{ccc} & & 0.816 \\ & & (0.001) \\ & & -0.013 \\ & & (0.309) \\ -0.027 & 0.688 & -0.004 \\ (0.001) & (0.000) & (0.722) \\ 0.024 & -0.108 & -0.025 \\ (0.000) & (0.241) & (0.002) \\ 0.023 & -0.272 & \\ (0.317) & (0.469) & \\ 0.007 & & \\ (0.095) & & \\ & -0.740 & \\ & (0.369) & \\ & -14.97 & \\ & (0.292) & \end{array}$

$-14.97$

(0.292)

$\begin{array}{lll}23.37 & 0.115 & 3.56\end{array}$

$\begin{array}{lll}(\mathbf{0 . 0 0 0}) & \mathbf{( 0 . 7 0 0 )} & \mathbf{( 0 . 0 1 9 )}\end{array}$

$\begin{array}{ll}0.189 & -2.55\end{array}$

$\begin{array}{lcc} & (0.204) & (0.001) \\ -2.59 & 0.542 & \end{array}$

$\begin{array}{cc} & 0.542 \\ -2.59 & (0.000)\end{array}$

$0.071 \quad-0.009$

$\begin{array}{ll}(0.000) & -0.009 \\ (0.859)\end{array}$

2.40

(0.001)

0.304

$(0.000)$

4.81
$(0.000)$

0.060

$(0.000)$

$-0.029$ (0.052) 
Table 11

Elasticities of human capital accumulation, $R \& D$ production, and steady-state output level

\begin{tabular}{|c|c|c|c|}
\hline & $\begin{array}{l}\text { Mobile and fixed- } \\
\text { line subscriptions }\end{array}$ & $\begin{array}{l}\text { Electricity } \\
\text { production }\end{array}$ & $\begin{array}{c}\text { Infrastructure } \\
\text { quality synthetic } \\
\text { index }\end{array}$ \\
\hline \multicolumn{4}{|l|}{$\begin{array}{l}\text { Human capital } \\
\text { accumulation }\end{array}$} \\
\hline Education expenditure $\left(v_{l}\right)$ & - & - & 0.402 \\
\hline Stock of infrastructure $\left(v_{2}\right)$ & 1.02 & 0.741 & 1.55 \\
\hline \multicolumn{4}{|l|}{ R\&D production } \\
\hline R\&D expenditure $\left(\varphi_{I}\right)$ & 0.356 & 0.258 & 0.479 \\
\hline Stock of patents $\left(\varphi_{2}\right)$ & 0.501 & 0.396 & 0.542 \\
\hline Stock of infrastructure $\left(\varphi_{3}\right)$ & 0.308 & 0.693 & - \\
\hline Quality of infrastructure & - & - & - \\
\hline \multicolumn{4}{|l|}{ Growth of GDP pc } \\
\hline Stock of infrastructure & 0.060 & 0.377 & 0.200 \\
\hline Quality of infrastructure & 0.033 & 0.502 & 0.0003 \\
\hline \multicolumn{4}{|c|}{$\begin{array}{l}\text { Notes: Elasticity values based on coefficient estimates of Table 8. For details see notes at bottom of Table } \\
\text { 3. The elasticity of the steady-state output level with respect to the quality of electric power (quality } \\
\text { infrastructure index) is calculated by dividing the coefficient estimate of electric power quality (quality } \\
\text { index) in the growth regression by the coefficient estimate of GDP per capita in the same regression and } \\
\text { multiply the finding by the mean value of the quality of electricity production (quality infrastructure } \\
\text { index). }\end{array}$} \\
\hline
\end{tabular}


Table 12

Testing for threshold effects of infrastructure

(1)

Telephone lines

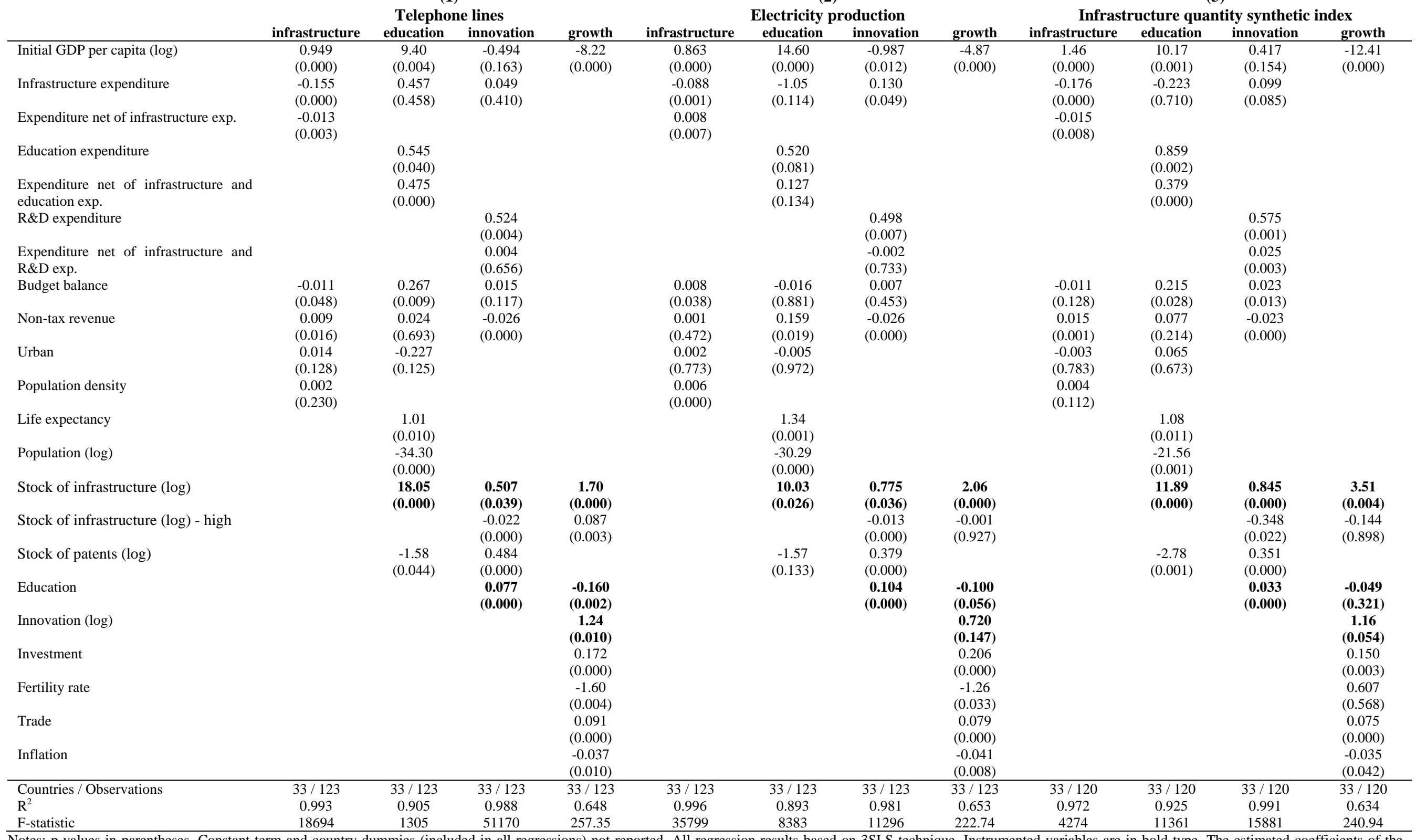
endogenous variables are qualitatively the same when we use the rest of the estimation techniques. 
Table 13

Elasticities of human capital accumulation, $R \& D$ production, and steady-state output level

\begin{tabular}{|c|c|c|c|}
\hline & $\begin{array}{l}\text { Mobile and fixed- } \\
\text { line subscriptions }\end{array}$ & $\begin{array}{l}\text { Electricity } \\
\text { production }\end{array}$ & $\begin{array}{c}\text { Infrastructure } \\
\text { quantity synthetic } \\
\text { index }\end{array}$ \\
\hline \multicolumn{4}{|l|}{ Human capital accumulation } \\
\hline Education expenditure $\left(v_{l}\right)$ & 0.103 & 0.098 & 0.162 \\
\hline Stock of infrastructure $\left(v_{2}\right)$ & 1.20 & 0.667 & 0.791 \\
\hline \multicolumn{4}{|l|}{ R\&D production } \\
\hline R\&D expenditure $\left(\varphi_{l}\right)$ & 0.308 & 0.292 & 0.338 \\
\hline Stock of patents $\left(\varphi_{2}\right)$ & 0.484 & 0.379 & 0.351 \\
\hline Stock of infrastructure $\left(\varphi_{3}\right)$ & 0.507 & 0.775 & 0.845 \\
\hline Stock of infrastructure $\left(\varphi_{3}\right)$ - high & 0.485 & 0.762 & 0.497 \\
\hline \multicolumn{4}{|l|}{ Growth of GDP pc } \\
\hline Stock of infrastructure & 0.206 & 0.422 & 0.282 \\
\hline Stock of infrastructure $\left(\varphi_{3}\right)$ - high & 0.217 & 0.422 & 0.282 \\
\hline
\end{tabular}

Notes: Elasticity values based on coefficient estimates of Table 10. For details see notes at bottom of Table 3 . 